\title{
MANCHESTER
}

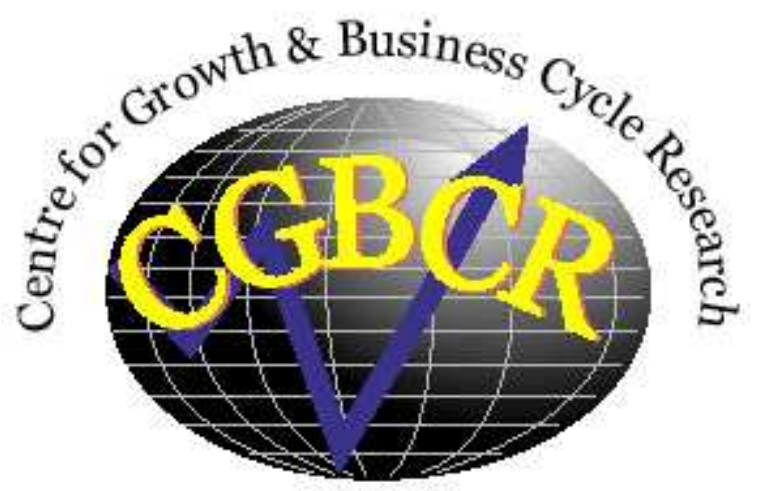

Discussion Paper Series

\section{Entrepreneurs, Risk Aversion and Dynamic Firms}

By

Neus Herranz, Stefan Krasa, Anne P. Villamil

Centre for Growth and Business Cycle Research, Economic Studies, University of Manchester, Manchester, M13 9PL, UK

September 2013

Number 189

Download paper from:

http://www.socialsciences.manchester.ac.uk/cgbcr/discussionpape rs/index.html 


\title{
Entrepreneurs, Risk Aversion and Dynamic Firms
}

\author{
Neus Herranz ${ }^{*} \quad$ Stefan Krasa ${ }^{\dagger} \quad$ Anne P. Villamil \\ February 14, 2013
}

\begin{abstract}
This paper conducts a theoretical and quantitative analysis of how entrepreneurs choose firm size, capital structure, default, and owner consumption to manage firm risk, including how these choices change with risk aversion. We decompose an entrepreneur's default decision into three elements: the fraction of firm debt; the potential reduction in personal consumption from losing the firm; and the ratio of personal wealth to firm scale, which determines an entrepreneur's ability to inject personal funds to continue operation. Data from the Survey of Small Business Finances is used to calibrate the model and estimate entrepreneur risk aversion. We determine the evolution of entrepreneur net worth, consumption, and firm assets over time. We find that many entrepreneurs have lower net worth and consumption than non-entrepreneurs with the same preferences, but the densities of the distributions of consumption and net-worth have wide upper tails. Thus, entrepreneurship can be a path toward great wealth and high consumption for the top quantiles of entrepreneurs.
\end{abstract}

JEL Classification Numbers: D92, E01, G33, G38, L25, L26

Keywords: Entrepreneur; Risk Aversion; Endogenous Default; Credit Constraints; Financial Structure; Heterogeneity; SSBF

${ }^{*}$ Herranz: University of Illinois, Department of Economics, 1407 W. Gregory Street, Urbana, IL 61801 USA; mherranz@illinois.edu

$\dagger$ Krasa: University of Illinois, Department of Economics, 1407 W. Gregory Street, Urbana, IL 61801 USA; skrasa@illinois.edu

†Villamil: University of Manchester, Centre for Growth and Business Cycle Research, Oxford Road, Manchester M13 9PL, UK \& University of Illinois, Department of Economics, 1407 W. Gregory Street, Urbana, IL 61801 USA; avillami@illinois.edu

We thank Marco Cagetti, George Deltas, Tim Kehoe, Makoto Nakajima, Stephen Parente, Vincenzo Quadrini and especially discussants Cristina De Nardi, Jamsheed Shorish, Yiannis Vailakis, two referees, and an editor. We also thank seminar participants at Cambridge, Oxford, University of London, the conferences on Bankruptcy at the IHS in Vienna, GE at Warwick University, SAET, SWET and the Milton Friedman Institute-Chicago FED Conference on Finance and Development. We gratefully acknowledge financial support from National Science Foundation grant SES-031839, NCSA computation grant SES050001, the Academy for Entrepreneurial Leadership at the University of Illinois and Kauffman Foundation grant 20061258. Any opinions, findings, and conclusions or recommendations expressed in this paper are those of the authors and do not necessarily reflect the views of the National Science Foundation or any other organization. 


\section{Introduction}

Willingness to take risks has a long tradition as an important characteristic of successful entrepreneurs, see Cantillon (1755). One view suggests that entrepreneurs may be less risk averse than the population at large, e.g., Knight (1921) and Kihlstrom and Laffont (1979). An alternative view is that entrepreneurs are particularly skilled at managing their exposure to risk. For example, Paul Brown in Forbes reports that entrepreneurs "don't like risk. They accept it as part of the game and then work extremely hard to reduce it to a minimum." ${ }^{1}$ We evaluate these views in a dynamic model in which entrepreneurs manage risk by selecting firm size, capital structure, default, and their own consumption. Individuals are risk averse, have access to a constant returns to scale production technology, and a given amount of initial private wealth.

Entrepreneurs can invest personal funds in their firm, and borrow from an outside lender, e.g., a bank. In each period the entrepreneur chooses the scale of investment and the fraction that is selffinanced. The remaining fraction of firm capital is borrowed from the lender via a debt contract with an interest rate (or face value) that equates the lender's expected payoff to the cost of funds. In the next period the project's random return is realized and the entrepreneur chooses whether to repay the loan or default. If firm assets are not sufficient to repay the debt, the entrepreneur can use private assets to cover the difference. If instead default is chosen, firm assets are liquidated at a cost, assigned to the lender, and the entrepreneur is excluded from the credit market and unable to operate a firm for several periods. The paper has four main results.

First, we decompose an entrepreneur's default decision into three elements: the initial level of firm debt, the reduction in personal consumption from losing the firm, and the ratio of personal wealth to firm size. In static models, only the first effect is present and default occurs if and only if firm assets are less than debt. In contrast, in our dynamic model continuing to operate the firm has an option value. As a consequence, an entrepreneur may choose to inject additional personal funds to pay the firm's debt to avoid default. The entrepreneur's ability to bail out the firm depends on the ratio of personal wealth to firm size, which we refer to as the "wealth-asset ratio effect." Willingness to bail out the firm depends on a "consumption loss effect," which is the entrepreneur's permanent loss in consumption from shutting down the firm. We show that these two effects are monotone in risk aversion, but move in opposite directions. More risk averse entrepreneurs run smaller firms in comparison to their wealth, i.e., the wealth-asset ratio is large, and they are better able to inject personal funds into their firms. Willingness to avoid default is smaller, however, since losing a small firm results in a small consumption loss. Quantitative analysis is necessary to

\footnotetext{
${ }^{1}$ http://wWw. forbes.com/sites/actiontrumpseverything/2012/04/12/are-you-risk-adverse-you-could-be-the-perfect-entrepreneur
} 
determine the outcome of these countervailing effects, which we provide in a calibrated model.

Second, we identify an existence problem that arises when firm scale is variable. Running an extremely (i.e., infinitely) leveraged firm can be profitable because if the failure rate is less than one, the entrepreneur's payoff may be infinite. The lender gets the entire project with probability close to one, and unless liquidation costs are very high, this is enough to cover the lender's cost of funds. Existence of a solution to the firm's problem must rule out such "gambling" by both parties. We do this by introducing a borrowing constraint, where the borrowing limit is set endogenously to a level at which the constraint does not bind locally, i.e., the Lagrange multiplier on the constraint is zero. ${ }^{2}$ This problem would not arise if firm or investment size were fixed.

Third, we calibrate the model and show that with the endogenous borrowing constraint firms are more leveraged and entrepreneurs invest less wealth in the firm than in the data. This leads to larger firm size, but a smaller fraction of entrepreneurs because more default and are subsequently excluded from the credit market. We then use the model to estimate a borrowing constraint that better matches the data. The Lagrange multiplier is positive, indicating that entrepreneurs are credit constrained. This tighter constraint leads to a lower default rate that is consistent with data. We find that up to a $50 \%$ reduction in default can occur, relative to the case where the constraint does not bind. We also permit risk aversion to differ, and use the model to estimate it. We find modest differences, with a median level of 1.6, in line with Mazzocco (2006) and parameter values used in the real business cycle literature. Thus, entrepreneurs do not seem to have very low risk aversion, rather they seem to use firm size, capital structure, default and consumption to manage risk.

Finally, we investigate the evolution of entrepreneur net worth, consumption, and firm assets over time, with tight and locally slack credit constraints. Cagetti and De Nardi (2006) and others document that the path towards wealth is closely connected with entrepreneurship. In our model entrepreneurs are willing to sacrifice significant consumption, using retained earnings to grow their firms, in hope of achieving high wealth in the future. Although success may often elude them, the high potential gains of entrepreneurship, the downside protection from bankruptcy, and the ability to manage risk through firm size and capital structure explains entrepreneurs' willingness to try.

In the remainder, section 2 contains stylized facts. Section 3 specifies the model, an individual agent's problem, considers existence and characterizes default. Section 4 maps the model to U.S. data, discusses model fit, and analyzes the dynamic effects of risk aversion. Section 5 concludes.

\footnotetext{
${ }^{2} \mathrm{~A}$ local constraint means that if a much larger loan were possible, agents could gamble. This problem is distinct from standard Ponzi schemes, as it would occur even in a two period model.
} 


\section{Stylized Facts about Small Firms}

We want the model to be consistent with several stylized facts, largely from the Survey of Small Business Finances (SSBF). This survey is administered by The Board of Governors of the Federal Reserve System and the U.S. Small Business Administration. Conducted in 1987, 1993, 1998, and 2003, each survey is a cross sectional sample of about 4000 non-farm, non-financial, non-real estate small businesses that represent about 5 million firms. ${ }^{3}$ The surveys contain information on the characteristics of small firms and their primary owner (e.g., owner age, industry, type of business organization), firm income statements and balance sheets, details on the use and source of financial services, and recent firm borrowing experience including trade credit and equity injections.

Fact 1: Small firm returns are very risky.

Table 1 provides summary statistics for real return on assets for small firms in the $1993 \mathrm{SSBF}^{4}$ The median return is $9.4 \%$ and the mean is $30 \%$. SSBF firms are noticeably risky, as the standard deviation indicates, with the high risk somewhat compensated by a high mean. About $12 \%$ of SSBF firms lost more than $20 \%$ of assets invested in the firm (debt plus equity), $7.4 \%$ lost more than $40 \%$, and $3.8 \%$ lost more than 100\%. Returns can also be substantial: $20.7 \%$ exceeded $50 \%$, $10.4 \%$ exceeded $100 \%$, and $3.8 \%$ exceeded $200 \%$. Skew is positive. The $95 \%$ confidence bands are computed using bootstrap sampling. For the median, the interquartile range is reported.

Table 1: Real Firm Return Summary Statistics, 1993 SSBF

\begin{tabular}{||l|ccccc||}
\hline \hline moment & median & mean & standard dev. & skewness & kurtosis \\
\hline \hline 1993 SSBF & 1.094 & 1.30 & 1.57 & 13.2 & 290 \\
$95 \%$ conf. & {$[1.08,1.11]$} & {$[1.22,1.38]$} & {$[0.95,2.13]$} & {$[2.3,17.3]$} & {$[29,488]$} \\
\hline \hline
\end{tabular}

Figure 1 shows that returns are not distributed normally. It compares the empirical ROA distribution to a normal distribution with the same mean and variance. The empirical distribution is tighter around the median than a normal distribution because variance is generated by some firms that do exceptionally well, which also generates the high kurtosis in table 1 . Figure 1 also shows that returns can be negative. To understand why this occurs, consider for example an entrepreneur who starts a bakery by borrowing $\$ 5,000$ from a bank for machines, uses trade credit to acquire perishable inputs worth $\$ 2,000$, and hires an employee who will be paid a salary of $\$ 3,000$ at the end of the period. Suppose the business fails and earns $\$ 0$. If only the bank's investment is

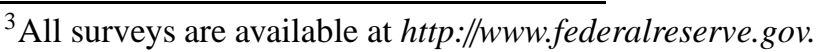

${ }^{4}$ Only the 1993 survey has the interest expenses required to compute the return on assets (ROA). See section 6.2.
} 


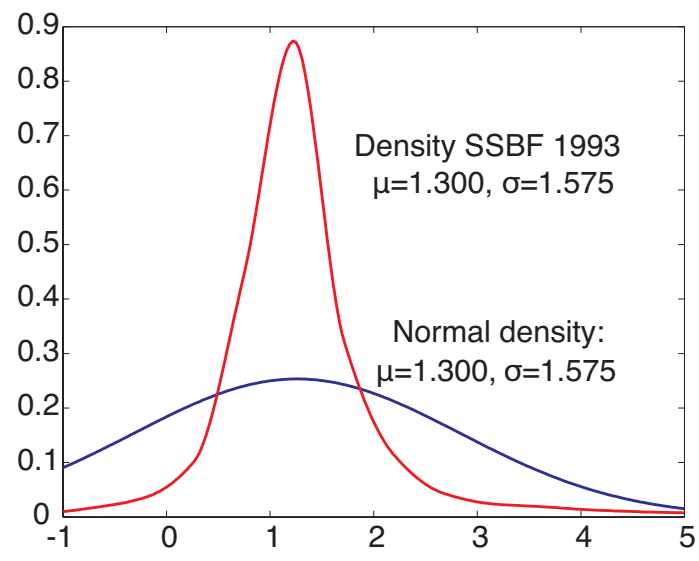

Figure 1: Empirical firm return pdf versus normal pdf, SSBF 1993

recorded in the data, a total firm loss of $\$ 10,000$ on an initial investment of $\$ 5,000$ is reported, a gross return on assets of $-1 .^{5}$

Fact 2: Owners invest substantial personal net-worth in their firms.

Table 2 reports the percentage of personal net-worth invested by entrepreneurs in their firm in the 1998 SSBF. $^{6}$ The median amount of net-worth invested is $21 \%$, but the data indicate a surprising lack of diversification for some entrepreneurs: $3 \%$ invest more than $80 \%$ of personal networth in their firm, $11 \%$ invest more than $60 \%$ and $25 \%$ invest more than $40 \%$. This concentration of personal funds in a business is puzzling in view of the risky returns documented by table 1.

Table 2: Net-Worth Invested, $1998 \mathrm{SSBF}$

\begin{tabular}{||l|cccc||cc||}
\hline \hline$\%$ net-worth invested & $\geq 20 \%$ & $\geq 40 \%$ & $\geq 60 \%$ & $\geq 80 \%$ & mean & median \\
\hline \hline$\%$ of entrepreneurs & $52 \%$ & $25 \%$ & $11 \%$ & $3 \%$ & $27 \%$ & $21 \%$ \\
\hline \hline
\end{tabular}

Fact 3: Most owners work at their firms.

For incorporated firms, the percentage of primary owners who work at their firms is $79 \%, 89 \%$

\footnotetext{
${ }^{5}$ The worker and trade credit supplier absorb the losses of $\$ 3,000$ and $\$ 2,000$, respectively. This standard accounting issue does not matter for the quantitative part of our paper, except for a loan rate adjustment. See Michelacci and Quadrini (2005) for a theoretical model of wage dynamics where workers implicitly provide trade credit since wages are paid ex-post.

${ }^{6}$ Owner net-worth is listed only in the $1998 \mathrm{SSBF}$, consisting of personal net-worth plus home equity. We report percent net-worth invested for incorporated firms with positive net-worth outside the firm, for firms with non-negative equity and assets of at least $\$ 50,000$. This lower bound on assets is the smallest number that did not generate numerical problems in our empirical analysis but left almost all of the sample intact.
} 


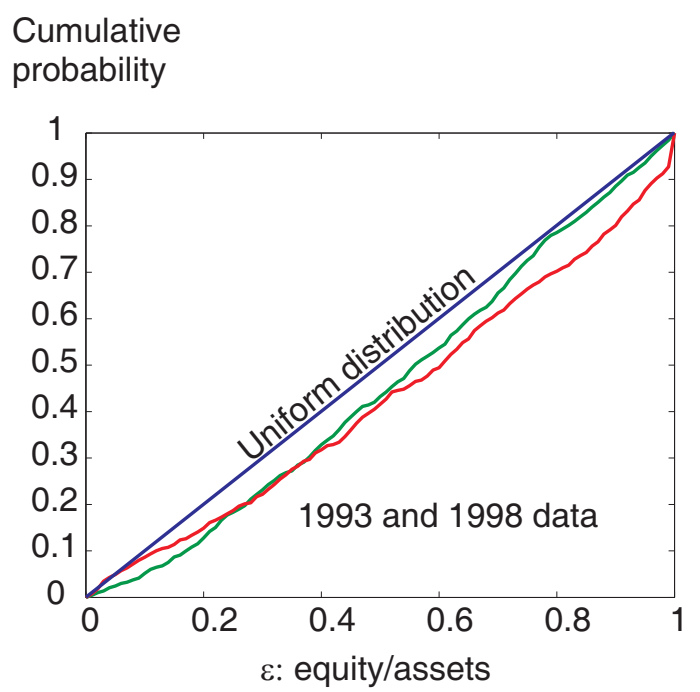

Figure 2: Cdfs of Equity/Assets for firms with positive equity: 1993 and 1998 SSBF Data

and $87 \%$ in the respective 1993, 1998 and 2003 SSBFs. This compounds the risk return puzzle because if the firm fails, owners lose the funds invested and their jobs.

Fact 4: The average annual default rate on small business loans is 3.5-4.5\%.

Glennon and Nigro (2005) find the default rate on small business loans guaranteed by the Small Business Administration is 3.5\% and Boissay and Gropp (2007), table 2.4, find a default rate on trade credit of $4.5 \%$ for small French firms (trade credit is a third of all firms' total liabilities in most OECD countries.)

Fact 5: Incorporated firms' negative equity is $15.7 \%$ in 1993 and $21.0 \%$ in 1998.

Negative equity means that firm liabilities exceed assets, making it likely that the firm needs additional funds, which could be the owner's personal funds or unpaid bills absorbed by creditors.

Fact 6: The distribution of firm capital structure is uniform.

Figure 2 shows that the cdfs of Equity/Assets in the 1993 and 1998 SSBF are approximately uniform. By definition, total assets consist of debt plus equity, thus Equity/Assets is a measure of firm capital structure. The approximately uniform cdfs, observed in both data sets, indicate that all capital structures are equally likely. This empirical fact for the distribution of all firms, of course, does not preclude a particular firm from having a determinate structure. If capital structure of individual firms is optimal and the distribution is uniform, the data suggest agent heterogeneity. 
The facts show that small firm returns are risky. Owners invest significant personal net worth and are likely to work at the firm, which compounds the risk. Many firms have negative equity, yet the default rate is low. Why do firms forbear in the face of such poor performance? Put differently, why do these entrepreneurs not default on their loans? Finally, all debt-equity ratios are equally likely, indicating heterogeneity. We now construct a model that is consistent with these facts.

\section{The Model}

Consider an economy with $t=0,1, \ldots$ time periods. A risk-neutral competitive lender has an elastic supply of funds and makes one-period loans. ${ }^{7}$ We begin by considering the problem of an individual, with discount rate $\beta$ and a CRRA utility function over consumption

$$
u(c)=\frac{c^{1-\rho}-1}{1-\rho} .
$$

This individual has initial endowment $w_{0}$ and access to a constant returns to scale production technology. If the individual operates the technology, the firm produces output $x$ per unit of assets invested $A$. The firm's return is given by random variable $X$ with cumulative distribution function $F(x)$ and probability density function $f(x)$, which is strictly positive on support $[\underline{x}, \bar{x}]$ with $\underline{x} \leq 0$, $\bar{x}>0$, and $x$ iid across periods. A negative realization means firm losses in a year exceed current assets, and the owner either uses personal funds to stay solvent or defaults. ${ }^{8}$ In all periods $t \geq 1$, the individual's net-worth $w_{t}$ is derived from the return on investment in the firm and in an alternative investment opportunity with return $r$. Net-worth is known at the beginning of each period.

An entrepreneur is an individual who runs a firm by making an investment $A>0 .{ }^{9}$ At any time $t$, the entrepreneur chooses the fraction of self-finance (equity) $\epsilon$, and debt finance $1-\epsilon$. The total amount of self-finance is therefore $\epsilon A$ and the entrepreneur's opportunity cost of funds is $\epsilon A(1+r)$. For the total amount of funds borrowed, $(1-\epsilon) A$, the entrepreneur owes $\bar{v} A$ next period. Thus, the loan rate is given by $r_{L}=\bar{v} /(1-\epsilon)-1$. The face value of debt $\bar{v}$, or equivalently $r_{L}$, is determined endogenously from the lenders' break even condition, given the risk free rate on the lenders' cost of funds $r_{f}$. In summary, there are two exogenous interest rates, $r$ and $r_{f}$, and the endogenously determined loan rate $r_{L}$. In the model calibration, we will allow $r$ to be larger than $r_{f}$. This reflects

\footnotetext{
${ }^{7}$ We consider a composite lender that supplies all liabilities (bank loans, trade credit and other liabilities) and can infer borrower risk aversion. The average maturity on loans to small firms is less than one year in the Federal Reserve's Survey of Terms of Business Lending (these firms lack audited financial statements, payment or profit histories, or verifiable contracts with workers, suppliers or customers).

${ }^{8}$ As we explained, this can occur if the firm has trade credit or if the loan has an overdraft provision. In the data, this corresponds to the case where the firm has negative equity and defaults.

${ }^{9}$ An individual that does not wish to run a firm sets $A=0$.
} 
the fact that net worth $w_{t}$ includes less liquid assets, such as home equity or retirement savings, that are more costly to use. In the calibration the endogenous loan rate $r_{L}$ will exceed $r$, i.e., the cost of debt is higher than self-finance if there is no default. This cost advantage of self-finance is counterbalanced by the fact that in the case of default an entrepreneur with more debt-finance will lose less personal funds.

After production occurs the firm has assets $A x$ and liabilities $A \bar{v}$, and the entrepreneur chooses whether to repay loan $A \bar{v}$ or default. ${ }^{10}$ When default occurs, bankruptcy follows immediately and is described by two parameters, $\delta$ and $T$. A court determines the total value of firm assets and transfers $1-\delta$ to the lender, where $\delta$ is a deadweight bankruptcy loss (e.g., firm assets are sold at a loss). ${ }^{11}$ Since the firm is incorporated, the entrepreneur is protected by limited liability and only firm assets can be seized. If bankruptcy occurs, the entrepreneur does not have access to the firm's returns for $T$ periods, which has two interpretations. First, corresponding to Chapter 7 in the U.S. Bankruptcy Code, the firm may be liquidated. Because bankruptcy remains on a credit record for a period of time, creditors and customers would be unwilling to do business with the entrepreneur during this period. Second, corresponding to Chapter 11, the firm may continue to operate, but is owned by the debt-holders who make investments and receive payments, or shut it down. After $T$ periods the credit record is clean, and the entrepreneur can either restart a new firm or regain control of the original firm, in Chapter 7 or 11 respectively.

The timing of events for incorporated firms is as follows:

1. Beginning of period $t$ (ex-ante) entrepreneur net-worth is $w$. There are two cases:

(a) The entrepreneur did not declare bankruptcy in any of the previous T periods: Choose consumption $c$, firm assets $A$, self-finance $\epsilon$ (debt is $1-\epsilon$ ), and amount $A \bar{v}$ to repay, subject to the lender receiving at least ex-ante expected payoff $(1-\epsilon) A\left(1+r_{f}\right)$.

(b) The entrepreneur declared bankruptcy $k$ periods ago. The owner cannot operate the firm for the next $T-k$ periods. Hence, only current consumption is chosen.

2. At the end of period $t$ (ex-post) the firm's return on assets, $x$, is realized. Total end-of-period firm assets are $A x$. The entrepreneur must decide whether or not to default. If

\footnotetext{
${ }^{10} \mathrm{~A}$ firm may default if it is unable to repay $A \bar{v}$ (firm plus personal assets are less than $A$ ) or is unwilling to repay. The entrepreneur can "bail out the firm" with personal assets to forestall bankruptcy, but cannot be forced to do so. The owner's personal credit history affects business loans, causing a credit interruption. Mester (1997) p. 7 finds that in small business loan scoring models, "the owner's credit history was more predictive than net worth or profitability of the business" and "owners' and businesses' finances are often commingled."

${ }^{11}$ Athreya (2004) considers an additional cost, stigma, which would lower the default rate.
} 
(a) Default: Only firm assets are seized. The entrepreneur is left with personal net-worth $(1+r)(w-\epsilon A-c)$, invested at outside interest rate $r$.

(b) No Default: Entrepreneur net-worth is $A(x-\bar{v})+(1+r)(w-\epsilon A-c)$, which includes both net-equity in the firm and the return on personal assets.

\subsection{The Problem of an Individual Entrepreneur}

Consider the optimization problem of an individual entrepreneur, with a given coefficient of risk aversion $\rho$ and net-worth $w$ at the beginning of the period. We state the problem recursively. Our initial goal is to determine the structure of the value function. If bankruptcy occurred in the previous $T$ periods, then the state is given by $(B, k, w)$ where $k$ is the number of periods since default and $B$ denotes bankruptcy. Otherwise, the state is given by $(S, w)$, and $S$ denotes solvency. Denote the value functions by $V_{B, k}(w)$ and $V_{S}(w)$, respectively. After $T$ periods the firm can restart, thus $V_{B, T}(w)=V_{S}(w)$. Let $\mathfrak{B}$ denote the set of asset return realizations $x$ for which bankruptcy occurs, with complement $\mathfrak{B}^{c}$. We specify a problem for each default state.

If the firm did not default in the previous $T$ periods, the individual solves:

Problem $1 V_{S}(w)=\max _{c, A, \epsilon, \bar{v}} u(c)+\beta\left[\int_{\mathfrak{B}} V_{B, 1}((1+r)(w-\epsilon A-c)) d F(x)\right.$

$$
\left.+\int_{\mathfrak{B}^{c}} V_{S}(A(x-\bar{v})+(1+r)(w-\epsilon A-c)) d F(x)\right]
$$

\section{Subject to:}

$$
\begin{gathered}
\int_{{\mathfrak{B} \cap \mathbb{R}_{-}}} x d F(x)+\int_{\mathfrak{B}_{\mathbb{R}_{+}}}(1-\delta) x d F(x)+\int_{\mathfrak{B}^{c}} \bar{v} d F(x) \geq(1-\epsilon)\left(1+r_{f}\right) \\
x \in \mathfrak{B} \text { if and only if } V_{B, 1}((1+r)(w-\epsilon A-c))>V_{S}(A(x-\bar{v})+(1+r)(w-\epsilon A-c)) \\
(1-\epsilon) A \leq b w \\
c \geq 0, A \geq 0,0 \leq \epsilon \leq 1 .
\end{gathered}
$$

The objective is the utility of current consumption plus the discounted continuation value of end of period net-worth. Constraint (1) ensures that the lender is willing to supply funds. The righthand-side indicates the fraction, $1-\epsilon$, of funds the lender invests in the firm must earn at least reservation return $1+r_{f}$. The left-hand side is the lender's expected return from the loan per unit 
of assets $A$ : The first term permits $x<0$, which are losses absorbed by the lender in default. The second term is the net amount the lender can recover from the firm in default, when there is a positive amount to seize (deadweight loss $\delta$ arises only if $x>0$ and the firm has not lost more than the value of its assets in the period). The third term is the fixed debt repayment when the firm is solvent. Constraint (2) specifies ex-post optimality of the default decision: An entrepreneur defaults if and only if the expected continuation payoff after default exceeds that from solvency. ${ }^{12}$ Borrowing constraint (3) may limit business loans to fraction $b$ of entrepreneur net-worth. We discuss this constraint in the next section. (4) is standard. ${ }^{13}$

Now consider the problem of a firm that defaulted $k \leq T$ periods ago. After $T$ periods the firm can operate again, thus $V_{B, T}(\cdot)=V_{S}(\cdot)$. Let $w^{\prime}$ denote net-worth next period:

Problem $2 V_{B, k}(w)=\max _{c, w^{\prime}} u(c)+\beta V_{B, k+1}\left(w^{\prime}\right)$

Subject to:

$$
\begin{gathered}
c(1+r)+w^{\prime} \leq w(1+r) \\
c, w^{\prime} \geq 0 .
\end{gathered}
$$

The objective of problem 2 is expected ex-ante utility. If default occurred the entrepreneur cannot run the firm for $T$ periods and chooses only consumption and saving, given budget constraint (5) and non-negativity constraint (6).

Theorem 1 uses the fact that CRRA utility is scalable in wealth to determine the structure of the value function, which allows us to restate Problem 1 as a one-dimensional fixed point problem. The proof is in Appendix B.

Theorem 1 Suppose that the entrepreneur has constant relative risk aversion. Let $v_{S}=V_{S}(1)$ and $v_{B, k}=V_{B, k}(1)$. Then $V_{S}(w)=w^{1-\rho} v_{S}$ and $V_{B, k}(w)=w^{1-\rho} v_{B, k}$.

Applying Theorem 1 to Problem 2, it is straightforward to compute $v_{B, k}$ as a function of $v_{S}$. We need only $v_{B, 1}$, the continuation utility given that default was just announced, and $v_{S}$. To

\footnotetext{
${ }^{12}$ Bailing out the firm with personal funds means that the entrepreneur continues to operate the firm even if $x<\bar{v}$. In a one period model (instead of the dynamic model) both $V_{B, 1}$ and $V_{S}$ would be the identity mapping, and (2) would reduce to $x \in \mathfrak{B}$ if and only if $(1+r)(w-\epsilon A-c)>A(x-\bar{v})+(1+r)(w-\epsilon A-c)$, which implies $x \in \mathfrak{B}$ if and only if $x<\bar{v}$ (bankruptcy occurs only if the return is less than debt plus interest).

${ }^{13}$ Ex ante $0<\epsilon<1$, but ex-post negative equity may occur. This distinction arises because the non-negativity constraint on equity only applies ex ante. Ex-post, if the project realization is low, assets are low and end-of-period equity will be negative due to the accounting identity: assets $=$ debt + equity.
} 
simplify notation, write $v_{B}$ for $v_{B, 1}$. Lemma 1 and Lemma 2 in Appendix B prove that the investor's constraint binds and bankruptcy set $\mathfrak{B}$ is a lower interval with cutoff $x^{*}$. Thus, the problem can be rewritten as follows, where all endogenous variables are expressed as a fraction of net-worth $w$ :

Problem $3 v_{S}=\max _{c, A, \epsilon, \bar{v}} u(c)+\beta v_{B} \int_{\underline{x}}^{x^{*}}[(1+r)(1-\epsilon A-c)]^{1-\rho} d F(x)$

$$
\left.+\beta v_{S} \int_{x^{*}}^{\bar{x}}[A(x-\bar{v})+(1+r)(1-\epsilon A-c)]^{1-\rho} d F(x)\right]
$$

Subject to:

$$
\begin{gathered}
\int_{\underline{x}}^{x^{*}} \min \{(1-\delta) x, x\} d F(x)+\int_{x^{*}}^{\bar{x}} \bar{v} d F(x)=(1-\epsilon)\left(1+r_{f}\right) \\
x^{*}=\max \left\{\bar{v}-\left[1-\left(\frac{v_{B}}{v_{S}}\right)^{\frac{1}{1-\rho}}\right] \frac{(1+r)(1-\epsilon A-c)}{A}, \underline{x}\right\} \\
c+\epsilon A \leq 1 \\
(1-\epsilon) A \leq b \\
c \geq 0, A \geq 0,0 \leq \epsilon \leq 1 .
\end{gathered}
$$

The objective is the utility of current consumption and the discounted value of end of period networth, for the default set, $\left[\underline{x}, x^{*}\right)$, and the solvency set, $\left[x^{*}, \bar{x}\right]$. Constraint (7) corresponds to lender individual rationality constraint (1), and binds by Lemma 1 in Appendix B. Constraint (8) is the optimal default cutoff and follows from (2) by Lemma 2. (9) ensures feasibility and (10) is the borrowing constraint. (11) is obvious.

\subsection{Existence, Uniqueness and the Borrowing Constraint}

The individual's problem is stated for a given risk aversion parameter $\rho$. In this section we show that solutions to Problem 3 exist unless risk aversion is below a cutoff value, and we explain the borrowing constraint's role in ensuring boundedness of the constraint set. We consider risk aversion and the borrowing constraint separately in order to better understand their distinct roles. We first state the main existence result. The proofs are in Appendix B. 
Theorem 2 There exist $\underline{\rho}<1$ and $\bar{r}>\frac{1}{\beta}-1$ such that Problem 3 has a solution for all $\rho \geq \underline{\rho}$ and for all $r \leq \bar{r}$.

In the proof, $\Lambda\left(v_{S}\right)$ is expected utility given continuation value $v_{S}$. In general $\Lambda^{\prime}\left(v_{S}\right)>1$ for all $v_{S}$ close to 0 . Thus, $\Lambda$ is not a contraction mapping and the standard fixed point theorem for contraction mappings does not apply. Instead, the proof shows that $\Lambda(0) \leq 0$ and $v_{S}$ exists such that $\Lambda\left(v_{S}\right) \geq 0$ for risk aversion $\rho>1$. As a consequence of the intermediate value theorem, continuity of $\Lambda$ implies that $\Lambda$ has a fixed point. By continuity, the result extends for some $\rho<1 .{ }^{14}$

\subsubsection{Non-existence for Low Risk Aversion}

No solutions exist for $\rho<\underline{\rho}$ because the product of $\beta$ and expected gross return $1+r$ exceeds 1 , and an individual with sufficiently low risk aversion would defer consumption indefinitely. This is obvious for a risk-neutral individual and by continuity extends to moderately risk averse entrepreneurs. In order to better understand the model, we compute the lower-cutoff for existence $\underline{\rho}$ in the simple case where the investment technology is deterministic and there is no outside finance. We make the latter assumption to show that non-existence depends on the scalability of the project but not on an entrepreneur's ability to choose the firm's financial structure.

Let $i$ denote investment, $R$ denote its return, and $e$ denote endowments. The entrepreneur solves the following optimization problem:

$$
\max _{c_{t}, i_{t}, t \in \mathbb{N}} \sum_{t=0}^{\infty} \beta^{t} \frac{c_{t}^{1-\rho}-1}{1-\rho} \quad \text { subject to } c_{t}+i_{t+1}=e_{t}+R i_{t}
$$

The first order conditions yield: $c_{t+1}=(R \beta)^{1 / \rho} c_{t}$, or $c_{t}=(R \beta)^{t / \rho} c_{0}$. It is easy to check that if this solution for $c_{t}$ is substituted into the objective, the sum is finite if $\underline{\rho}>1-\frac{\ln (1 / \beta)}{\ln (R)}$. We can get existence for lower $\rho$ by reducing $\beta$, but this is not economically plausible (i.e., entrepreneurs become too impatient to make sizeable investments).

The failure of existence for very low levels of risk aversion depends crucially on flexible investment size. If project size is fixed at $\bar{A}$, then utility is always bounded because consumption each period can be at most $\bar{A} R$.

\footnotetext{
${ }^{14}$ If more than one solution to the recursive problem exists, the solution with the maximal $v_{S}$ corresponds to the solution of the infinite horizon problem where agents select sequences for consumption, assets, debt-equity and default.
} 


\subsubsection{Non-Existence without the Borrowing Constraint}

We now show that absent borrowing constraint (10) solutions to Problem 3 may not exist, because a firm's ability to choose scale and capital structure results in a "gambling" problem, where entrepreneurs would run extremely (i.e., infinitely) leveraged firms.

Assume that investment project $X$, bankruptcy $\cos t \delta$, and the risk-free rate $r_{f}$ satisfy

$$
E[X]>1+r_{f}-\delta
$$

In table 1 in section $2, E[X]=1.3$. The risk-free rate in the U.S. is below 5\%, thus (13) is satisfied even if bankruptcy losses are a quarter of firm assets. Boyd and Smith (1994) find $\delta$ is $10 \%$. Bris, Welch, and Zhu (2006) estimate costs of 0-20\% of assets, which implies that (13) holds.

To see that no solution exists to the entrepreneur's optimization problem if (13) is not satisfied, choose $\epsilon_{n}, A_{n}$ such that $\epsilon_{n} A_{n}=1 / n$ and $A_{n} \rightarrow \infty$, i.e., the entrepreneur increases firm size to infinity, but equity in the firm converges to zero at the same time. Let $\bar{v}_{n}$ be the face value of the debt that satisfies borrowing constraint (10) from Problem 3. Then (7) and (13) imply $\hat{v}=\lim \sup _{n \rightarrow \infty} \bar{v}_{n}<\bar{x}$, else the left-hand side of (7) is strictly larger than the right-hand side. As a consequence, (8) implies that $x^{*} \rightarrow \hat{v}$ since $(1+r)\left(1-\epsilon_{n} A_{n}-c\right) / A_{n}=(1+r)(1-(1 / n)-c) / A_{n} \rightarrow 0$, in other words the probability of default is strictly bounded away from 1 . Thus, as $n \rightarrow \infty$ the entrepreneur's payoff converges to infinity since

$$
\lim _{A_{n} \rightarrow \infty} \beta v_{S} \int_{\hat{v}}^{\bar{x}}\left[A_{n}(x-\bar{v})+(1+r)\left(1-\epsilon_{n} A_{n}-c\right)\right]^{1-\rho} d F(x)=\infty
$$

Intuitively, the entrepreneur runs an infinitely sized firm, but defaults with probability below 1. As a consequence, he receives an infinite payoff with positive probability. At the same time the investor gets all of the project return most of the time, which is sufficient to cover the lender's cost of funds. In this case, the entrepreneur's optimization problem has no solution. The borrowing constraint remedies this. The problem is not related to existence problems caused by Ponzi schemes. Instead, it is generated by the entrepreneur's ability to choose both firm size and capital structure, which allows the entrepreneur to run an extremely leveraged firm. ${ }^{15}$

\subsubsection{Locally Slack Borrowing Constraints}

Borrowing constraints are essential in dynamic models with incomplete markets, but a key question is how to endogenize the constraint. Alvarez and Jermann (2000) establish a second wel-

\footnotetext{
${ }^{15}$ Our effect differs from Vereshchagina and Hopenhayn (2009), where entrepreneurs choose risky projects to generate lotteries that convexify the objective function.
} 
fare theorem for an economy with limited commitment, by introducing "not-too-tight" constraints on borrowing. These constraints, which are taken as given by agents in the competitive equilibrium, ensure that all market participants are willing to pay back their debt in all states, while simultaneously permitting as much risk sharing as possible. ${ }^{16}$ Chatterjee, Corbae, Nakajima, and Rios-Rull (2007), Livshits, MacGee, and Tertilt (2007), and Arellano (2008) consider models with incomplete markets where, unlike Alvarez and Jermann (2000), default occurs in equilibrium. For example, in Chatterjee, Corbae, Nakajima, and Rios-Rull (2007) borrowing is possible until the household's level of debt reaches a point at which the probability of repayment becomes zero. At this point the price of debt becomes zero, and no lender will provide additional funds. This approach does not work in our framework because of the non-existence problem: both the lender and the borrower are better off when the firm gambles by using extreme levels of leverage. Unlike in Chatterjee, Corbae, Nakajima, and Rios-Rull (2007), the repayment to the lender does not go to zero in our model even if the loan size goes to infinity.

To determine an analog of a not-too-tight constraint for our model we allow borrowing until gambling becomes an issue. Formally, this is achieved by defining a locally slack constraint. We use Problem 3 and relax $b$ until the Lagrange multiplier on constraint (10) is zero. At this point entrepreneurs are locally unconstrained, i.e., they would not want to increase their level of debt by any small amount. However, the entrepreneur is constrained from choosing a much larger loan that would lead to very high leverage and gambling. In the quantitative analysis we will investigate whether our locally slack constraint or a tighter constraint (lower $b$ ) better fits the data.

\subsection{Characterization of Default}

Knowing the shape of the value function, we can now derive a formula that links firm and owner characteristics to the default decision. In Problem 3, constraint (8) gives default cutoff $x^{*}$. We decompose $x^{*}$ into three distinct effects that we analyze individually. Let $c_{B}$ and $c_{S}$ be the constant consumption over time that would result in a utility of $v_{B}$ or $v_{S}$, respectively. It follows that

$$
\frac{c_{B}}{c_{S}}=\left(\frac{v_{B}}{v_{S}}\right)^{\frac{1}{1-\rho}} .
$$

Assuming that default occurs with positive probability, i.e., $x^{*} \geq \underline{x}$, bankruptcy constraint (8) is equivalent to

$$
x^{*}=\bar{v}-\left[\frac{c_{S}-c_{B}}{c_{S}}\right]\left[\frac{(1+r)(1-\epsilon A-c)}{A}\right] .
$$

\footnotetext{
${ }^{16}$ Martins-da Rocha and Vailakis (2011) introduce a refinement that results in a unique not-too-tight constraint.
} 
The default cutoff terms are: ex ante firm debt $\bar{v}$, the consumption loss from firm bankruptcy, and the entrepreneur's personal net wealth outside the firm over firm scale, which determines the entrepreneur's ability to inject more personal funds into the firm. In words,

$$
x^{*}=\text { ex-ante debt }- \text { consumption loss } \times \text { wealth-to-firm-scale ratio. }
$$

Consider the three forces that determine the default cutoff in $x^{*}$ :

Ex-ante debt: In static models, agents default if their assets $x$ are less than debt $\bar{v}$, and hence all firms with negative equity default, cf., Townsend (1979) and Gale and Hellwig (1985).

Consumption loss: This term measures the percentage decline in consumption from losing the firm, where $c_{S}$ and $c_{B}$ are the constant consumption streams that yield the same utility as the entrepreneur's actual consumption in solvency and bankruptcy states, respectively.

Wealth-to-firm-scale ratio: In order to prevent firm bankruptcy, an entrepreneur can inject personal assets held outside the firm to cover firm debt $\bar{v}$. This is easier to do if the firm is small relative to the entrepreneur's net-worth.

If only the first term were present, all firms with negative equity would default, and hence the fraction of firms with negative equity and the default rate would coincide. Facts 4 and 5 in Section 2 show there is in fact a big gap between the two numbers, which indicates the importance of the last two terms of (15). We now provide theoretical results that give insight into the relationship between risk aversion and the last two terms. Theorem 3 states conditions under which the consumption loss is decreasing in risk-aversion. The intuition is that more risk-averse agents invest a smaller fraction of their assets in the firm and, as a consequence, the difference between default and nondefault utility is small. Theorem 4 shows that the wealth-to-firm-scale ratio is decreasing as long as risk-aversion and default are not too large. Intuitively, more risk averse individuals run smaller firms and hence the ratio of wealth outside the firm to firm assets is large.

\section{Theorem 3}

1. Suppose that $(1+r) \beta=1$ and $T=\infty$. Then the consumption loss is decreasing in $\rho$.

2. For given $\rho$, there exists a $\bar{T} \in \mathbb{N}$, and $\eta>0$ such that the consumption loss is decreasing in $\rho$ for any $T \geq \bar{T}$, and $r$ and $\beta$ with $1-\eta<(1+r) \beta<1+\eta$.

We next show that $\epsilon$ and $A$ are both monotonically decreasing in $\rho$, i.e., a more risk averse individual will choose a higher debt-equity ratio and a lower project scale. 
Theorem 4 Suppose that $(1+r) \beta=1, T=\infty$, and that the borrowing constraint is locally slack. Let the density $f$ of return distribution $F$ be continuous, and assume that $F(x)=0$ implies $f(x)=0$. Then $\epsilon$ and $A$ are decreasing in $\rho$ for all sufficiently low levels of risk aversion and for sufficiently small default probabilities.

Theorem 4 indicates two major channels through which an entrepreneur can lower risk. First, the entrepreneur can run a project at a smaller scale. Ceteris paribus, this lowers the default probability since the wealth-to-firm-scale ratio is increased. Second, a more risk averse entrepreneur would wish to increase the project's leverage. In this case, leverage is not used to increase project scale, but rather to reduce the amount of entrepreneur funds tied up in the firm. As a consequence, more entrepreneur funds can be invested outside the firm at riskless rate $r$, providing a cushion if default occurs. The effect on the default probability from increased leverage is ambiguous: Ceteris paribus lowering $\epsilon$ raises the wealth-to-firm-scale ratio, which reduces default. However, reducing $\epsilon$ means the firm borrows more, increasing ex-ante debt level $\bar{v}$ (see constraint (7)), and raising the default probability. We will see in the calibrated model that the first effect dominates the second, and default is generally lower as $\rho$ decreases. We now calibrate the model to U.S. data.

\section{Mapping the Model to U.S. Data}

Table 3: Exogenous Parameters

\begin{tabular}{|c|c|c|c|}
\hline Parameter & Interpretation & Value & Comment/ Observations \\
\hline$r_{f}$ & lender opportunity cost & $1.2 \%$ & real rate, 6 mo T-Bill, 1992-2006 \\
$r$ & entrepreneur opportunity cost & $4.5 \%$ & real rate, 30 year mortgage, 1992-2006 \\
$\beta$ & discount factor & 0.97 & determined from $r$ and $r_{f}$ \\
$T$ & default exclusion period & 11 & U.S. credit record \\
$\delta$ & default deadweight loss & 0.10 & Boyd-Smith (1994) \\
$f(x)$ & pdf of firm returns & & SSBF 1993 (Appendix D) \\
\hline
\end{tabular}

We use U.S. data to assign values to five model parameters and the distribution of firm returns in table 3. We identify $r_{f}$, the lender's opportunity cost of short-term funds, with the average real return on 6 month Treasury bills between 1992 and 2006. ${ }^{17}$ The interest rate charged by the lender will be strictly higher than $r_{f}$ because of bankruptcy costs. We identify the owner's opportunity cost of funds $r$ with the real rate on 30 year mortgages over the period; the cost of using home equity to finance a business loan will also be strictly higher. $\beta=0.97$ is approximated

\footnotetext{
${ }^{17}$ We use monthly data for T-Bill rates and deduct for each month the CPI reported by the BLS.
} 
by $1 /\left(1+0.5 r_{f}+0.5 r\right)$, with $r$ and $r_{f}$ weighed equally (firm risk cannot be diversified since a portfolio of small firms does not exist). The bankruptcy exclusion parameter is $T=11$, because in the U.S. after 10 years past default is removed from a credit record. The bankruptcy deadweight loss is $\delta=0.1$, as in Boyd and Smith (1994) and the midpoint of $0-20 \%$ of assets in Bris, Welch, and Zhu (2006). Firm return distribution $f(x)$ is computed from SSBF data on incorporated firms, see section 6.2. The remaining parameters are jointly calibrated by choosing $\mu, \sigma$ and possibly $b$ to minimize the distance between model predictions and SSBF data.

\subsection{Heterogeneous risk aversion}

In order to match the SSBF data we must construct distributions, which in turn requires us to model a source of underlying heterogeneity. Because willingness to bear risk is at the heart of entrepreneurship, we extend the model specified for an individual agent to a setting where agents may be heterogeneous with respect to risk aversion parameter $\rho$. We first construct distributions in the SSBF, and then construct the counterpart implied by the model.

Empirical Distributions: We focus on three empirical distributions derived from SSBF data that are important for small firms: firm assets, personal net-worth invested in the firm, and the ratio of equity over assets. Since in our model all quantities are normalized by the entrepreneur's networth, we define them as follows:

$$
\begin{aligned}
& \text { Normalized net worth: } \mathfrak{w}=\frac{\text { owners' share } * \text { equity }}{\text { net-worth outside the firm }+ \text { owners' share } * \text { equity }} \\
& \text { Normalized assets: } \mathfrak{a}=\frac{\text { owners' share } * \text { asset }}{\text { net-worth outside the firm }} \\
& \text { Equity-Asset ratio: } \quad \mathfrak{e}=\frac{\text { owners' equity in firm }}{\text { firm assets }}
\end{aligned}
$$

We denote the cdfs of the empirical distributions by $W^{e}(\mathfrak{w}), W^{e}(\mathfrak{a})$, and $E^{e}(\mathfrak{e})$, respectively. We construct $W^{e}(\mathfrak{w})$ only for firms with non-negative equity, to avoid possible division by zero.

Distributions implied by the model: Let $\phi_{\mu, \sigma}(\rho)$ be a normal distribution over risk aversion, and $\Phi_{\mu, \sigma}(\rho)$ its cdf. Given firm return pdf $f(x)$ the following cdfs are predicted by the model:

Cdf of Net-Worth. After $x$ is realized, firm assets are $A(\rho) x$ and debt is $A(\rho) \bar{v}$. Equity in the firm is $A(\rho)(x-\bar{v}(\rho))$ - which is non negative if $x \geq \bar{v}(\rho)$, while the entrepreneur's net-worth outside the firm is $(1+r)(1-c(\rho)-\epsilon(\rho) A(\rho))$. The fraction of total net-worth invested is therefore

$$
\mathfrak{w}=\frac{A(\rho)(x-\bar{v}(\rho))}{A(\rho)(x-\bar{v}(\rho))+(1+r)(1-c(\rho)-\epsilon(\rho) A(\rho))} .
$$


We can solve (16) for $x=x(\mathfrak{w}, \rho)$. Since $\mathfrak{w}$ is strictly increasing in $x$, the entrepreneur's net-worth invested in the firm is less than or equal to $\mathfrak{w}$ if and only if $x \leq x(\mathfrak{w}, \rho)$. Finally, since we only use firms with positive equity to compute net-worth invested for the empirical distribution, we must do the same for the model predicted distribution, i.e., we restrict attention to firms with return realizations $x \geq \bar{v}(\rho)$. For firms with positive equity, the model-predicted cdf of net worth invested in the firm is therefore given by ${ }^{18}$

$$
W_{\mu, \sigma}^{m}(\mathfrak{w})=\frac{\int_{\bar{v}(\underline{\rho})}^{x(\mathfrak{w}, \underline{\rho})} f(x) \Phi_{\mu, \sigma}(\underline{\rho}) d x+\int_{\underline{\rho}}^{\infty} \int_{\bar{v}(\rho)}^{x(\mathfrak{w}, \rho)} f(x) \phi_{\mu, \sigma}(\rho) d x d \rho}{\int_{\bar{v}(\underline{\rho})}^{\infty} f(x) \Phi_{\mu, \sigma}(\underline{\rho}) d x+\int_{\underline{\rho}}^{\infty} \int_{\bar{v}(\rho)}^{\infty} f(x) \phi_{\mu, \sigma}(\rho) d x d \rho} .
$$

Cdf of Equity/Assets. After project return $x$ is realized, the fraction of equity is given by

$$
\mathrm{e}=\frac{A(\rho)(x-\bar{v}(\rho))}{A(\rho) x}
$$

Let $x=x(\mathrm{e}, \rho)$ solve (18). Then for firms with positive equity, the cdf of equity/assets is

$$
E_{\mu, \sigma}^{m}(\mathrm{e})=\frac{\int_{\bar{v}(\rho)}^{x(\mathrm{e}, \underline{\rho})} f(x) \Phi_{\mu, \sigma}(\underline{\rho}) d x+\int_{\underline{\rho}}^{\infty} \int_{\bar{v}(\rho)}^{x(\mathrm{e}, \rho)} f(x) \phi_{\mu, \sigma}(\rho) d x d \rho}{\int_{\bar{v}(\underline{\rho})}^{\infty} f(x) \Phi_{\mu, \sigma}(\underline{\rho}) d x+\int_{\underline{\rho}}^{\infty} \int_{\bar{v}(\rho)}^{\infty} f(x) \phi_{\mu, \sigma}(\rho) d x d \rho} .
$$

Cdf of End of Period Assets. The current realization of end of period assets as a fraction of net-worth outside the firm is:

$$
\mathfrak{a}=\frac{A(\rho) x}{(1+r)(1-c(\rho)-\epsilon(\rho) A(\rho))}
$$

Let $x=x(\mathfrak{a}, \rho)$ solve (20). Then the cdf of end of period assets is

$$
A_{\mu, \sigma}^{m}(\mathfrak{a})=\int_{\underline{x}}^{x(\mathfrak{a}, \underline{\rho})} f(x) \Phi_{\mu, \sigma}(\underline{\rho}) d x+\int_{\underline{\rho}}^{\infty} \int_{\underline{x}}^{x(\mathfrak{a}, \rho)} f(x) \phi_{\mu, \sigma}(\rho) d x d \rho .
$$

\subsection{Model Calibration}

Given the values for the exogenous model parameters in Table 3, we will use the model to compute the remaining parameters in both borrowing constraint cases:

Locally slack constraint: In this case only $\mu$ and $\sigma$ must be determined. Choose $\mu, \sigma$ to minimize the supnorm distance between the cdf implied by the model and the cdf from the SSBF data:

$$
\min _{\mu, \sigma \geq 0}\left\|W_{\mu, \sigma}^{m}(\mathfrak{w})-W^{e}(\mathfrak{w})\right\|_{\infty}+\left(0.431-\mathfrak{a}_{\mu, \sigma}\right)^{+}+\left(\mathfrak{a}_{\mu, \sigma}-0.519\right)^{+}
$$

\footnotetext{
${ }^{18}$ The denominator is the probability that the entrepreneur has positive equity, where $\rho$ is the lowest parameter for which a model solution exists. For all $\rho<\underline{\rho}$ we assign the model solution for $\underline{\rho}$ as explained in section 4.3.
} 
Table 4: Calibrated Parameters and Fit

\begin{tabular}{|c|c|c|c|}
\hline \multirow{2}{*}{ Parameter } & Interpretation & $\begin{array}{l}\text { Model } \\
\text { with } \\
\text { Endog. } \boldsymbol{b}\end{array}$ & $\begin{array}{l}\text { Model } \\
\text { with } \\
\text { Fixed } \boldsymbol{b}\end{array}$ \\
\hline$b \%$ & borrowing constraint: loan $\leq b w$ & NA & 21.5 \\
$\mu$ & median of distribution of risk aversion & 1.56 & 1.55 \\
$\sigma$ & standard deviation of distribution of risk aversion & 1.50 & 0.83 \\
\hline \hline fit & Distance to fitted cdf \& assets in (22) & 0.145 & 0.042 \\
\hline
\end{tabular}

The cdf of net-worth invested implied by the model, $W_{\mu, \sigma}^{m}(\mathfrak{w})$, is given by (17). The supremum norm $\|.\|_{\infty}$ is taken over all non-negative fractions of net-worth. ${ }^{19}$ The second and third terms impose penalties only for asset values outside the $95 \%$ confidence interval for firm assets, which Herranz, Krasa, and Villamil (2009) find is [43.1,51.9]. Since we exclude firms with negative equity when determining $W^{e}$, net-worth invested is between $0 \%$ and $100 \%$, but assets are unbounded. ${ }^{20}$

Tight constraint: In this case, solve problem (22) over $b, \mu, \sigma$.

\subsection{Performance of the Model}

Table 4 reports parameter values for both cases, first where $b$ varies endogenously such that the borrowing constraint is locally slack, and second where $b$ is determined by (22) for all entrepreneurs. In both cases the table shows that the median entrepreneur risk aversion is between 1.5 and 1.56. To put the estimates in perspective, Mazzocco (2006) uses the Consumer Expenditure Survey to estimate a median coefficient of risk aversion of 1.7 for men. While one may expect entrepreneurs to be somewhat less risk averse than the general population, the model indicates that matching the data does not require very low levels of risk aversion. We find that $\sigma$ is 1.50 or 0.83 for the two cases, where non-zero values indicate agent heterogeneity. ${ }^{21}$ Table 4 shows the model with a tight constraint has a better fit than the slack constraint, 0.042 versus 0.145 .

The left panel of figure 3 shows the cdf for net-worth invested in the SSBF data (red), the model

\footnotetext{
${ }^{19}$ To compute the supremum norm we evaluate $\left|W_{\mu, \sigma}^{m}(\mathfrak{w})-W^{e}(\mathfrak{w})\right|$ at 1,000 equi-distant points between 0 and 1 , and take the maximum.

${ }^{20}$ For example, $5 \%$ of firms had assets over ownership share that exceeded owner net-worth by $500 \%$.

${ }^{21}$ Mazzocco (2006) does not estimate the distribution of risk aversion, so his estimate of the standard deviation of 0.96 is not directly comparable to ours. The calibrated parameters do not vary significantly with legal parameters $\delta$ and $T$. The insensitivity to changes in $\delta$ is due to the low equilibrium default rate. The best model fit is obtained at a value of $T=13$. Thus, if we calibrate $T$ instead of choosing it to be consistent with U.S. institutions, the numbers for the calibrated parameters and model results do not change significantly.
} 

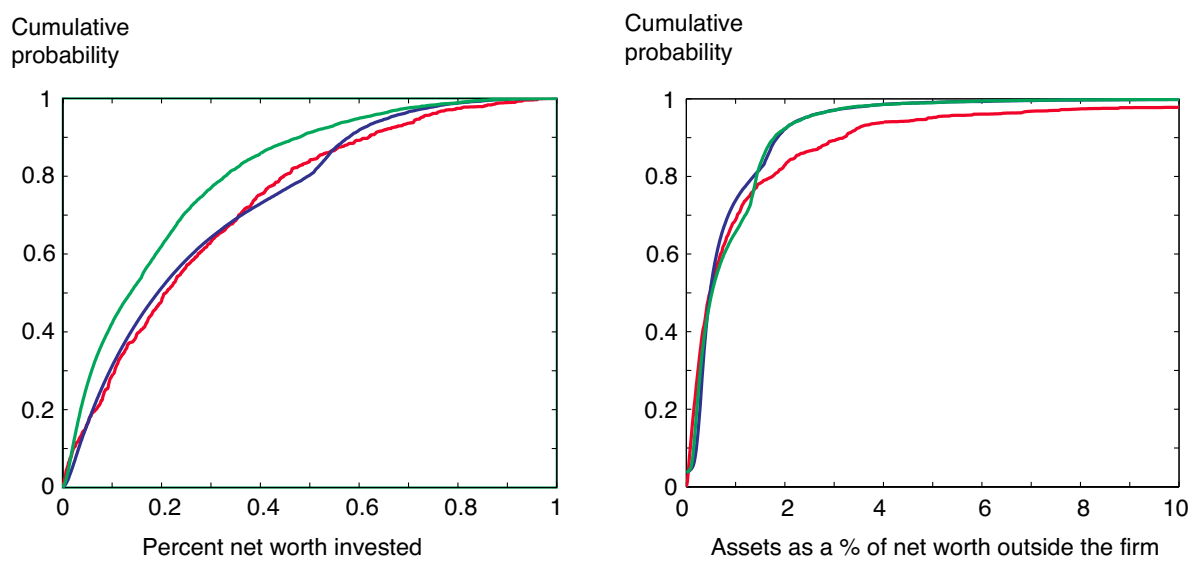

Figure 3: 1998 SSBF data and model with slack \& tight constraints: net-worth \& assets cdfs

with tight borrowing constraint $b$ (blue), and the locally slack constraint (green). ${ }^{22}$ The model with a slack constraint does not match the level that entrepreneurs invest in their firm. Intuitively, a slack constraint makes it possible for the entrepreneur to reduce risk by putting less personal funds at stake. This generates the higher level of default in table 5. The tighter credit constraint forces entrepreneurs to use more of their own money and this reduces default. ${ }^{23}$ The right panel shows asset levels in the SSBF data and the predictions of the two models. Both models do not match the assets of few large firms for reasons we explain below, but compared to each other the model results are similar. Table 5 shows the overall point predictions largely fall within the data ranges.

Our model is quantitatively plausible along a number of dimensions. As discussed above, the left panel of figure 3 shows the fraction of net-worth an owner invests in the firm. Since we fit to this empirical cdf one would expect to see a match, but the constrained model does a very good job replicating the facts in table 2 in section 2. Owners invest substantial personal net-worth in their firms: the median is $21 \%$ and the mean is $27 \%$. The right panel of figure 4 compares the predicted cdfs of firm assets to the data. The match is also good, but both models miss a few large firms. ${ }^{24}$ The model predicted median asset levels of $48.1 \%$ and $51.9 \%$ in table 5 are within the

\footnotetext{
${ }^{22}$ Only the 1998 SSBF has owner net worth, personal net-worth plus home equity. The data cdf for net-worth invested is for firms with positive net-worth outside the firm, non-negative equity, and at least $\$ 50,000$ in assets.

${ }^{23}$ Glover and Short (2011) also provide evidence that a tight credit constraint may apply for incorporated firms. They find that incorporated firms pay an interest rate premium compared to unincorporated firms, which they argue is a consequence of a "contraction in the supply of credit." In other words, the credit constraint binds.

${ }^{24}$ One reason the model predicts fewer very large firms is that solutions do not exist below $\rho=0.74$. At $\rho$, the exante level of $\epsilon$ and $A$ are 0.720 and 0.766 , respectively. Thus, end of period net-worth outside the firm, $\left(1-\epsilon A_{-}-c\right)(1+r)$ is about 0.470 . Using median return $\hat{x}=1.094$ from table 1 , the ex-post level of assets as a fraction of net-worth for risk aversion level $\rho$ is $A \hat{x} /(1-\epsilon A-c)(1+r)=1.786$. In the figure, this is where the model predicted curves move away from the (red) data.
} 

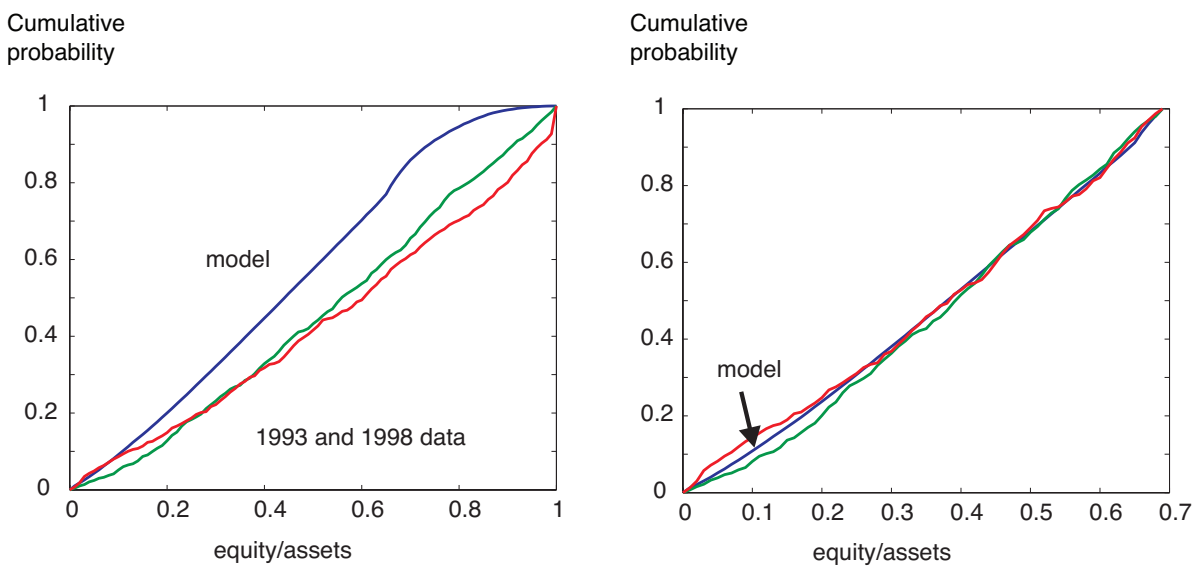

Figure 4: 1993 \& 1998 SSBF data and model with tight constraint: capital structure cdfs

$95 \%$ confidence interval of $[43.1,51.9]$.

Figure 4 compares the constrained model prediction (blue line) for firm capital structure to the cdfs for 1993 and 1998 SSBF data (red and green lines). The left panel shows that the model misses somewhat equity/assets. This occurs because no model solutions exist below $\underline{\rho}$. At $\underline{\rho}=0.74$ the associated value of $\bar{v}$ is 0.335 . At median return level $\hat{x}=1.094$, this gives an ex post value of equity/assets of $(\hat{x}-\bar{v}) / \hat{x}=0.7$, which is where the kink in the left panel occurs. If the cdf of $\epsilon$ is computed conditional on $\epsilon<0.7$, the model does an excellent job of replicating the empirical distribution of equity/assets among firms - see the right panel. By definition total assets are debt plus equity, thus equity/assets is a measure of firm capital structure. The approximately uniform cdf indicates that all capital structures are equally likely and this suggests agent heterogeneity, if individual firm capital structure is optimal.

Table 5: Point estimates: Borrowing constrained model, unconstrained model \& data

\begin{tabular}{|c|c|c|c|c|}
\hline Parameter & Interpretation & $\begin{array}{l}\text { Model } \\
\text { with } \\
\text { Endog. } \boldsymbol{b}\end{array}$ & $\begin{array}{l}\text { Model } \\
\text { with } \\
\text { Fixed } \boldsymbol{b}\end{array}$ & Data \\
\hline median $A \%$ & median firm assets (size) & 51.9 & 48.1 & {$[43.1,51.9]$} \\
consumption \% & consumption as a fraction of net worth & 3.2 & 3.6 & $3-5$ \\
default \% & average default rate & 6.4 & 4.4 & $3.5-4.5$ \\
neg. equity \% & negative equity in the firm & 16.1 & 10.6 & $15.7,21.0$ \\
\hline
\end{tabular}

Table 5 shows that the model replicates successfully other targets. Median firm assets match 
well (as discussed above) and consumption is in the standard range. ${ }^{25}$ The default point prediction for the model with the tight borrowing constraint is consistent with Fact 4 in section 2 that the average annual default rate is $3.5-4.5 \%$ on small business loans. The default prediction is higher for the model with the locally slack constraint. When the constraint is tight, $10.6 \%$ of firms have negative equity, which is below the empirical values for all firms of $15.7 \%$ in 1993 and $21.0 \%$ in 1998 , see fact 5 in section 2 . The value of $16.1 \%$ for the locally slack constraint is closer to these targets. In the next section we consider how these magnitudes vary with risk aversion.

\subsubsection{The Effect of Risk Aversion on Default and Negative Equity}

In Section 3.3 we identified three effects that determine default: (i) The ex-ante level of debt $\bar{v}$; (ii) the consumption loss from firm bankruptcy; and (iii) the wealth-to-firm-scale ratio. The first effect is the only one present in a static model, where a firm would default if and only if the return realization $x<\bar{v}$, i.e., if the firm has negative equity. The other two effects are a consequence of the value of continuing to operate a firm when equity is negative in a dynamic model.
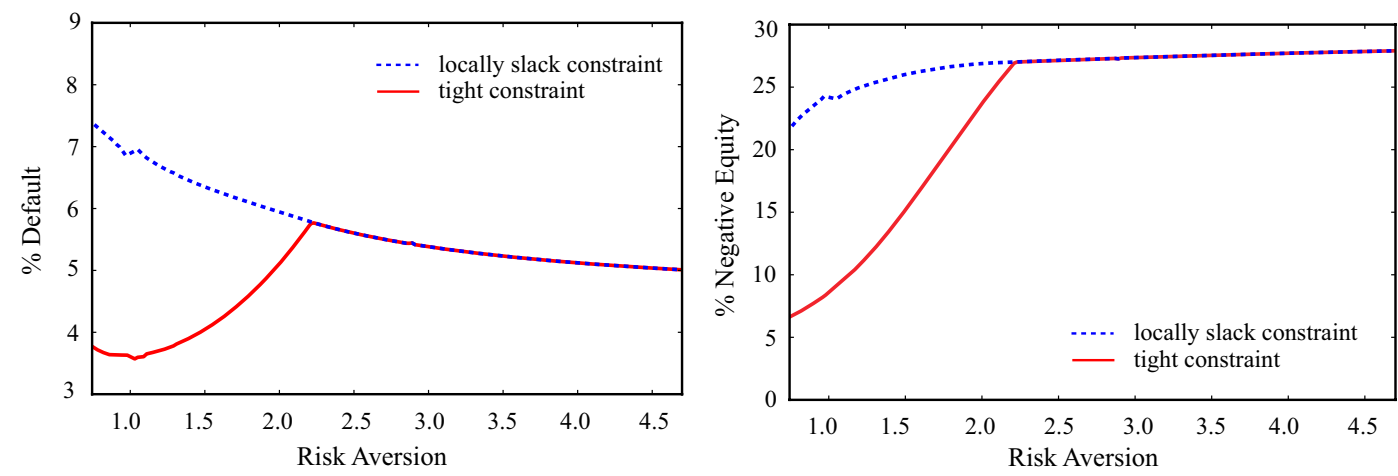

Figure 5: Model predicted default probabilities and negative equity as risk aversion varies

The left panel of figure 5 shows the default rate in our dynamic model. ${ }^{26}$ In both panels the solid lines indicate the model with a tight credit constraint (where $b$ is $21.5 \%$ ) and the dotted lines correspond to the locally slack constraint. When an individual's risk aversion reaches about 2.2, the credit constraint is slack in both models and the dotted and solid lines coincide. The right panel shows the fraction of firms that have negative equity for a given level of risk aversion. This would correspond to the default rate in a static model, where dynamic effects (ii) and (iii) are inoperative.

\footnotetext{
${ }^{25}$ Point estimates for the expected fraction of net-worth spent on consumption and the default probability are $c(\underline{\rho}) \Phi_{\mu, \sigma}(\underline{\rho})+\int_{\underline{\rho}}^{\infty} c(\rho) \phi_{\mu, \sigma}(\rho) d \rho$ and $\int_{\underline{x}}^{x^{*}(\mathrm{e}, \underline{\rho})} f(x) \Phi_{\mu, \sigma}(\underline{\rho}) d x+\int_{\underline{\rho}}^{\infty} \int_{\underline{x}}^{x^{*}(\mathrm{e}, \rho)} f(x) \phi_{\mu, \sigma}(\rho) d x d \rho$.

${ }^{26}$ The graphs are not smooth near $\rho=1$ due to roundoff errors as CRRA preferences converge to log utility.
} 

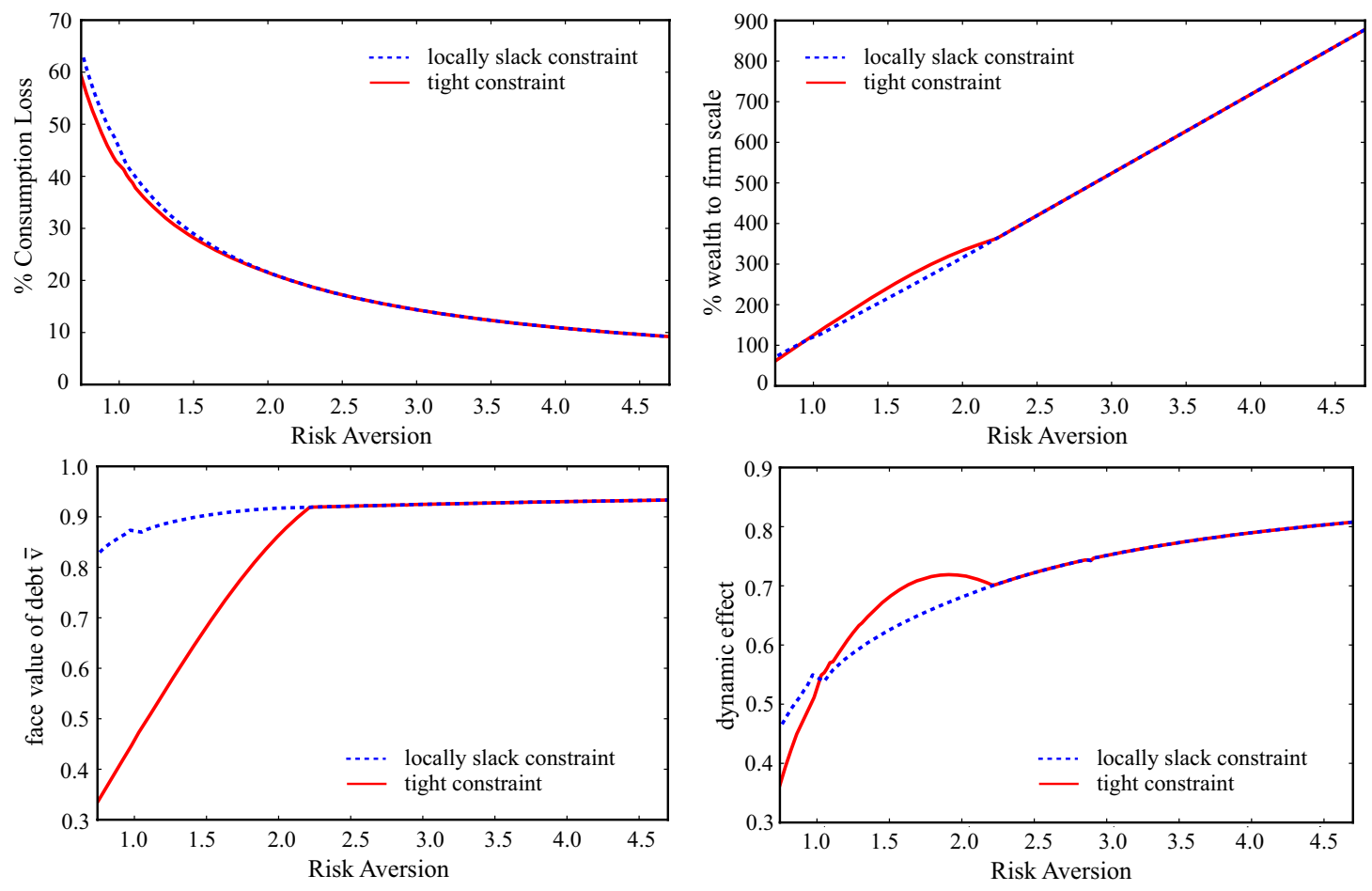

Figure 6: Default determinants: debt, consumption loss, wealth to size ratio \& dynamic effect

Our model indicates that these dynamic effects induce many firms with negative equity to continue to operate, thereby reducing the default rate. The gap between the fraction of negative equity and the default rate is especially strong for more risk averse entrepreneurs.

Figure 6 graphs the individual components of default. Recall from (15) that

$$
x^{*}=\text { ex-ante debt }- \text { consumption loss } \times \text { wealth-to-firm-scale ratio. }
$$

Theorem 3 proves the consumption hit from losing the firm is decreasing in risk aversion, which raises default cutoff $x^{*}$ as $\rho$ increases. We can see this monotonicity in the top left panel of figure 6 . Theorem 4 proves the wealth-to-firm-scale ratio is increasing in risk aversion, which we also see in the figure. The product of these two terms is the dynamic effect (bottom right panel) which is theoretically ambiguous. For the calibrated model with the locally slack constraint the dynamic effect is increasing in $\rho$, i.e., it reduces default as $\rho$ is increased. In the case of the tight constraint the dynamic effect is not monotone, but it is increasing for most $\rho$. The bottom left panel shows that $\bar{v}$ increases with $\rho$, which results in an increase in negative equity and default. The lower default in the model with the tight constraint when $\rho$ is low is primarily due to an entrepreneur's lower debt $\bar{v}$ in this range. Compared to the slack constraint, the bottom right panel shows that the dynamic effect provides additional default reduction when risk aversion is between 1 and 2.2, and a slight 

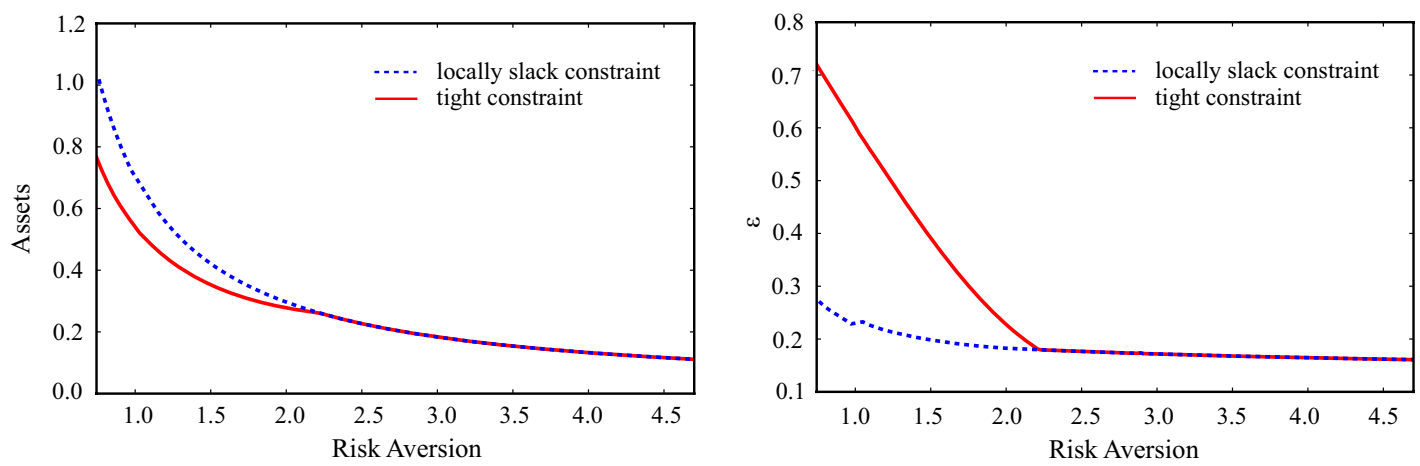

Figure 7: Effect of risk aversion on assets $(A)$ and the equity/asset ratio $(\epsilon)$

increase for levels lower than 1 , which results in the initial U-shape in the default probability in the left panel of figure 5 .

\subsubsection{The Effect of Risk Aversion on Loan Rates, Assets, Equity, and Consumption}

Theorem 4 proves that assets and the equity/asset ratio $\epsilon$ are decreasing in $\rho$, for sufficiently small $\rho$, for the model with the endogenous constraint. Figure 7 shows that these functions are indeed decreasing over the whole range of risk aversion for which we compute solutions. The intuition for the decrease in $A$ and $\epsilon$ was discussed after the statement of Theorem 4: Both the reduction in project scale and the increased use of outside funds reduce the entrepreneur's exposure to risk.
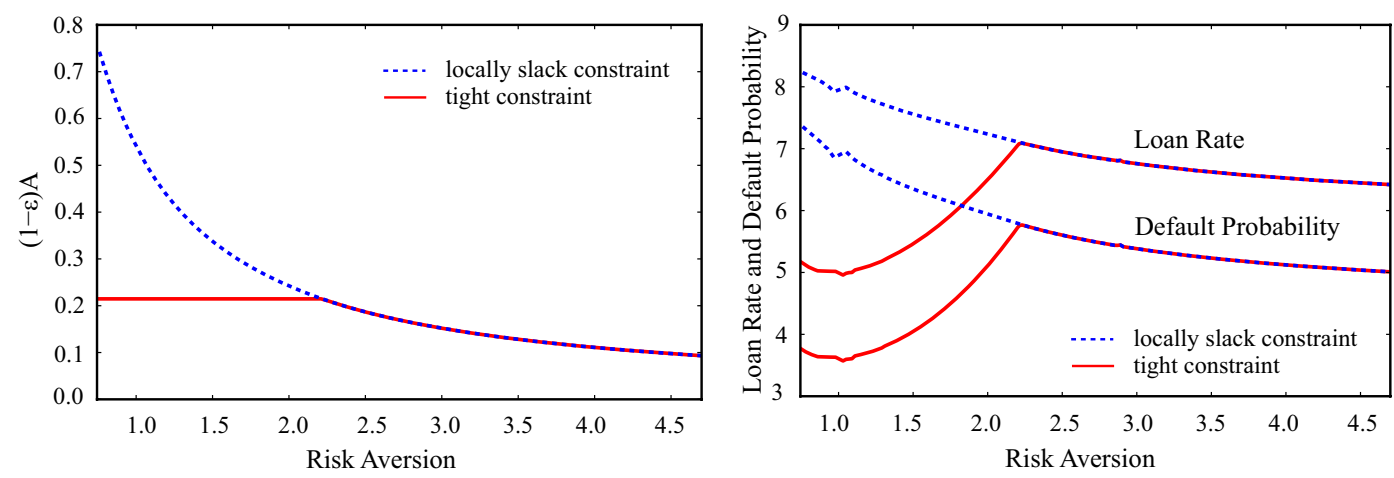

Figure 8: Effect of risk aversion on loans, $(1-\epsilon) A$, and interest rates

Consider figure 8 . The left panel shows the total amount of outside loans, $(1-\epsilon) A$. Theorem 4 indicates the overall effect of risk aversion on loans is theoretically ambiguous since $1-\epsilon$ increases, while $A$ decreases. In our calibrated model, $A$ decreases faster than $1-\epsilon$ increases, and outside 
loans decrease. ${ }^{27}$ When the constraint is tight, borrowing by entrepreneurs with sufficiently low risk aversion is constant and equal to $b=0.215$. The right panel of figure 8 shows that loan rates track default rates. Note that the loan rate on a debt contract with face value $\bar{v}$ and loan amount $1-\epsilon$ is given by $r_{L}=\frac{\bar{v}}{1-\epsilon}-1$. In the data some firm returns are negative, which means we must adjust this rate. Formally, suppose some amount of debt $\kappa A$ in the initial investment is not observed, where $0<\kappa<1$ (see the bakery example in section 2). Then the total amount of debt is $(1-\epsilon+\kappa) A$, resulting in an "adjusted" loan rate of $r_{L}^{a}=\frac{\bar{v}}{1-\epsilon+K}-1$. Since the lender is risk-neutral, the present value of the negative returns is $\kappa=\left(1 /\left(1+r_{f}\right) \int_{\underline{x}}^{0} x d F(x)\right.$.

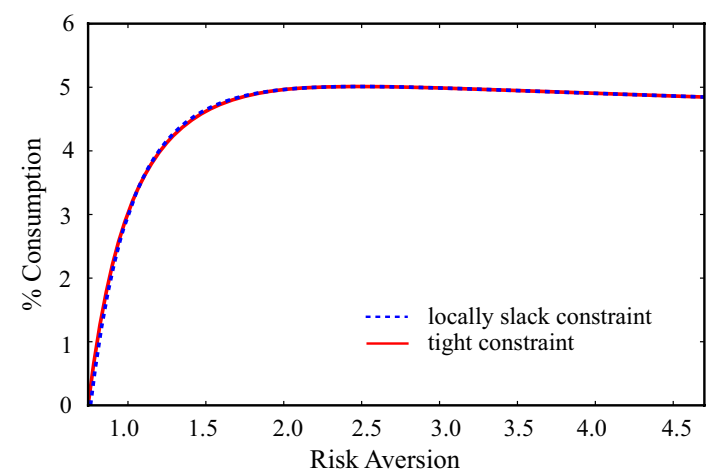

Figure 9: Effect of risk aversion on consumption

Figure 9 shows how consumption changes with risk aversion. The borrowing constraint has no effect on the outcome. At level of risk aversion $\underline{\rho}$, where solutions to the optimization problem start to exist, consumption is arbitrarily small. There are two reasons for this. First, the intertemporal elasticity of substitution is higher for lower $\rho$, which implies the entrepreneur is more willing to substitute current for future consumption. Second, the entrepreneur is more willing to bear risk and therefore forgoes current consumption to increase the project's scale.

\subsection{Dynamics of Consumption, Net-worth and Assets}

In this section we investigate the dynamics of entrepreneur consumption, net-worth and firm assets. In each time period, an entrepreneur receives a random project return, which determines consumption and net-worth in the following period. Figure 10 shows the density functions of the distribution of net worth and consumption after 5, 10, and 20 time periods for a person with risk

\footnotetext{
${ }^{27}$ Chen, Miao, and Wang (2010) study how risk aversion and idiosyncratic firm risk affect firm capital structure and default in a model with fixed scale and CARA preferences. The paper shows how the standard corporate finance approach breaks down when idiosyncratic risk cannot be diversified away. They find that borrowing rises with risk aversion, while it falls in figure 8 .
} 

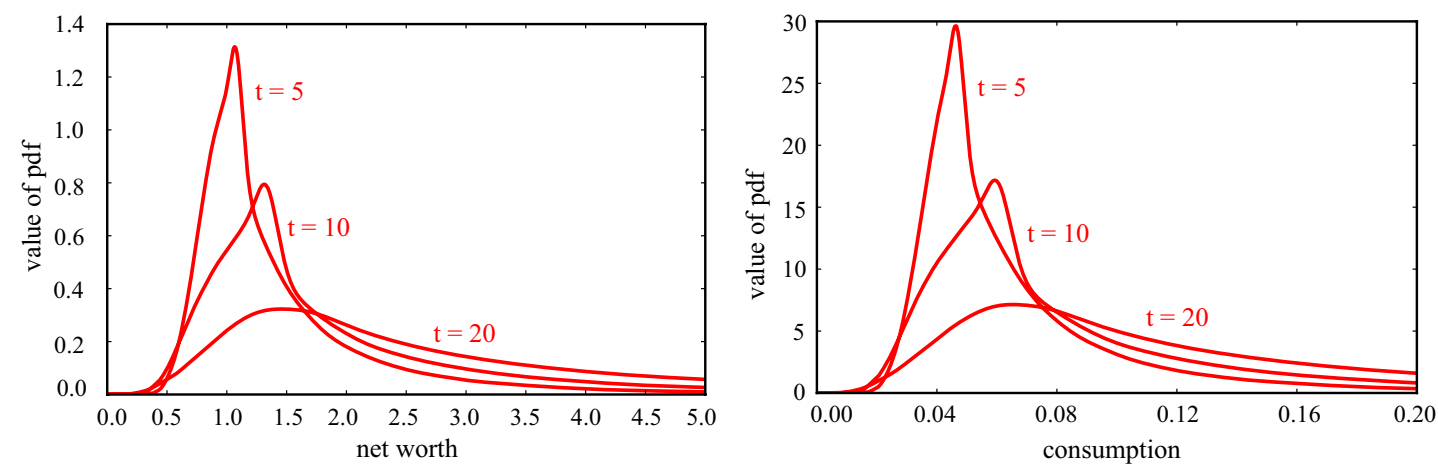

Figure 10: Pdf of net-worth and consumption for $\rho=1.5$ after 5, 10, and 20 time periods

aversion $\rho=1.5$, the model's estimate for the median entrepreneur. ${ }^{28}$ The densities shown are for the case of the locally slack constraint - the predictions of the model with the tight constraint are very similar. The density functions for consumption and net-worth are closely related, since consumption is the same fraction of net-worth in all non-default states. At the start of the model, net worth is normalized to 1 , but the density functions assign significant mass to points less than 1, which means that these unsuccessful entrepreneurs lost money. On the other hand, the densities have a "fat" upper tail, indicating that some entrepreneurs have the chance to be very successful.
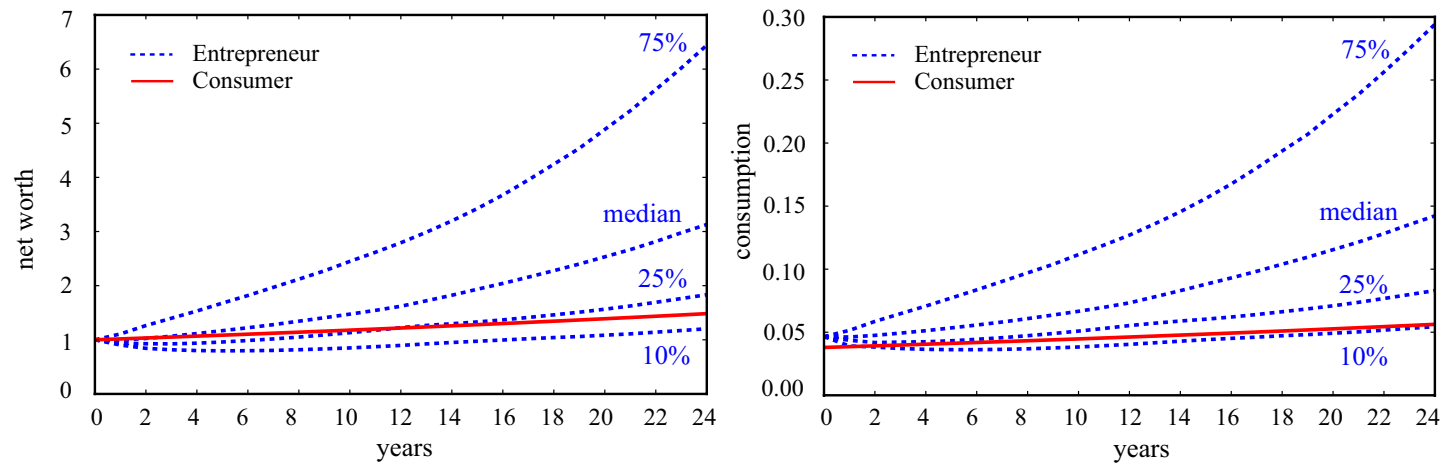

Figure 11: Entrepreneur \& non-entrepreneur dynamics, $\rho=1.5: 10 \%, 25 \%, 50 \%, 75 \%$ quantiles

We next compare quantiles of the distributions of net-worth and consumption for two types of individuals with risk aversion $\rho=1.5$ : an entrepreneur with access to a production technology and a non-entrepreneur whose consumption and net worth are based entirely on a deterministic

\footnotetext{
${ }^{28}$ To determine the density functions we first use Monte Carlo simulations to generate firm returns. We then determine the density function by applying a Gaussian kernel density estimation to the generated data.
} 
endowment. ${ }^{29}$ In figure 11, the solid lines show the deterministic net-worth and consumption profiles of the non-entrepreneur. The dashed lines are the 10\%, 25\%, median, and $75 \%$ quantiles of the distributions of the distributions for entrepreneurs. ${ }^{30}$ We find that the median entrepreneur has higher net-worth in all periods compared to the non-entrepreneur, and only the bottom $10 \%$ of entrepreneurs do worse. The wealth effect from having access to a project implies that all entrepreneurs have slightly higher consumption in the initial period, compared to non-entrepreneurs with the same utility function. Similarly, only the consumption of the bottom $10 \%$ of entrepreneurs is lower in subsequent periods, while the upside gains for the $75 \%$ quartile are substantial. The figure shows that entrepreneurs are very successful at minimizing the substantial downside project risks evident in the previous figure, while retaining access to the upside gains.
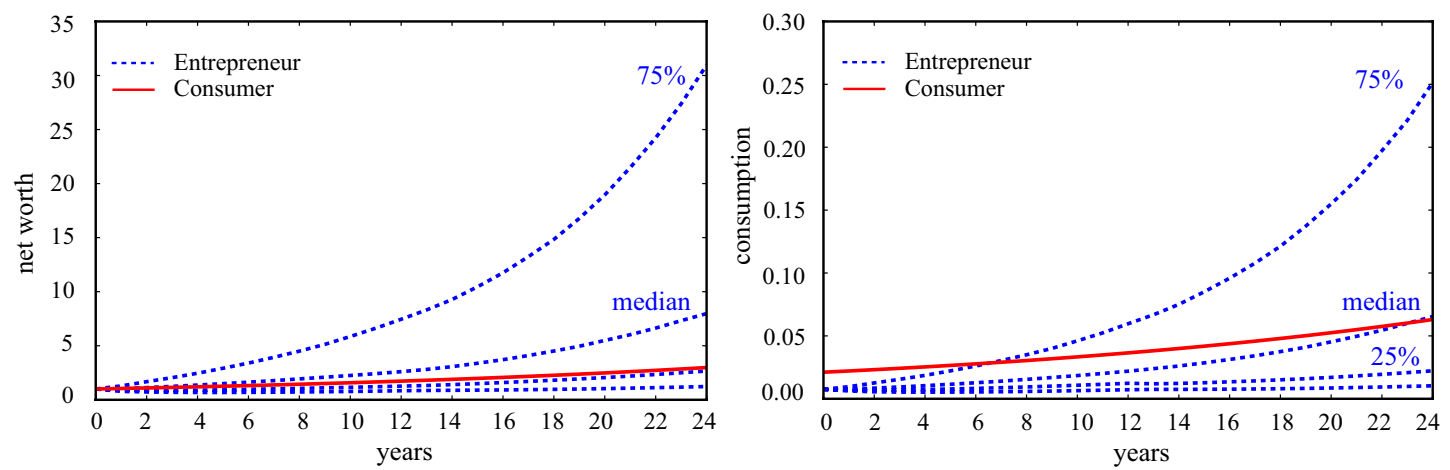

Figure 12: Entrepreneur \& non-entrepreneur dynamics, $\rho=0.8: 10 \%, 25 \%, 50 \%, 75 \%$ quantiles

Figure 12 compares the dynamics of an entrepreneur and non-entreprenuer (solid line), when both have with low risk aversion of $\rho=0.8$. Compared to figure 11 , lower risk aversion results in entrepreneurs willing to run projects at a larger scale, thereby risking bigger losses. Now the networth of the bottom $25 \%$, instead of just the bottom $10 \%$, is below that of the non-entrepreneur for all 24 time periods. On the other hand, the most successful quartile of entrepreneurs has a net-worth in period 24 that is about 5 times higher than the $\rho=1.5$ entrepreneurs. The lower risk aversion and increase in the intertemporal elasticity of substitution result in lower initial consumption for entrepreneurs. It takes 6 years for the top quartile to catch up to the consumption of the nonentrepreneur, while the median entrepreneur must wait 24 periods. The median entrepreneur also

\footnotetext{
${ }^{29} \mathrm{We}$ assume the non-entrepreneur has access to the same loans as the entrepreneur to focus solely on the difference between being endowed or not with a production technology.

${ }^{30}$ In each time period a different entrepreneur may be at a particular quantile. For example, a firm that ends up in the $75 \%$ after 20 years could have been at the bottom in the first few years and then experienced success in later years.
} 
ends up with net-worth that is only about two times that of the non-entrepreneur. If the entrepreneur had known at the outset that he would end up at the median, he likely would not have started the project. In contrast, for the top quartile entrepreneurship is a path toward wealth and high consumption. Thus, entrepreneurs with lower risk aversion are willing to significantly reduce their current consumption in the hope of a future reward that is far from certain. This attitude is reflected in comments made by David Siegel, CEO of Westgate Resorts, in a November 2012 E-mail to employees: ${ }^{31}$ "I started this company over 42 years ago. At that time, I lived in a very modest home. We didn't eat in fancy restaurants or take expensive vacations because every dollar I made went back into this company. Meanwhile, many of my friends... spent every dime they earned. They drove flashy cars and lived in expensive homes and wore fancy designer clothes. I put my time, my money, and my life into this business-with a vision that eventually, some day, I too, will be able to afford to buy whatever I wanted."
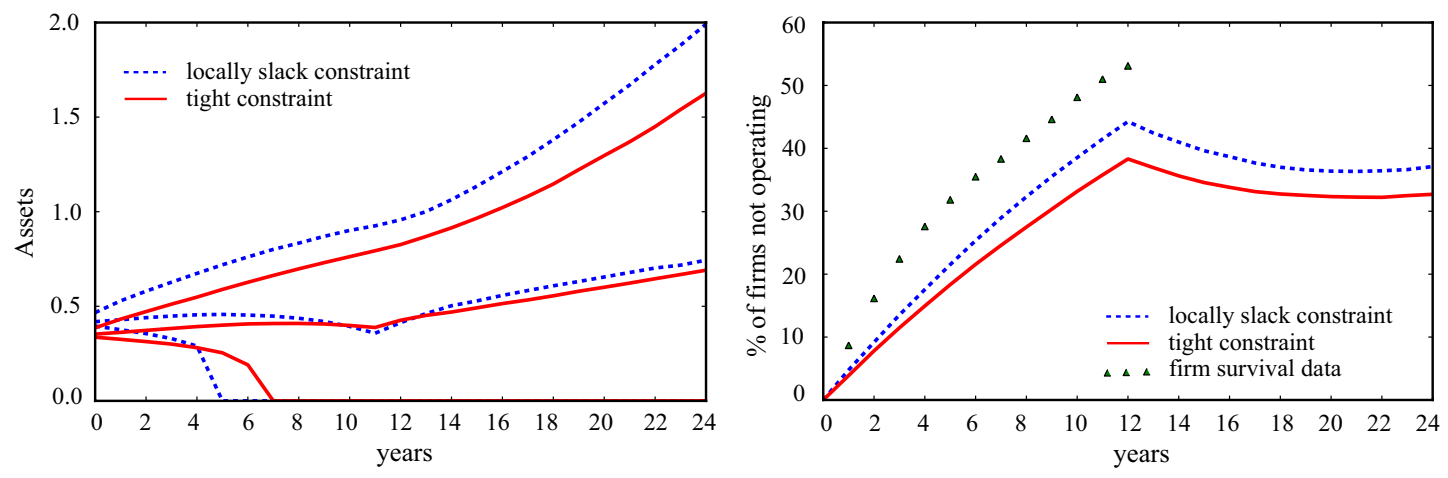

Figure 13: Dynamics of firm assets for $\rho=1.5$.

Finally, the left panel of figure 13 shows the dynamics of assets for the median entrepreneur with $\rho=1.5$ for the $25 \%, 50 \%$ and $75 \%$ quantiles. The top $25 \%$ of firms with a locally slack constraint are larger than those with a tight constraint. The median firm is about the same size under both regimes. For the bottom $25 \%$ firm size is zero after 5 years with the locally slack constraint and after 7 years for the tight constraint. Firm size becomes zero for 11 periods after default, when the firm is unable to operate. The fraction of firms that are not operating is shown in the right panel of figure 13. At $t=0$ we start with a cohort of entrepreneurs with $\rho=1.5$. The firms that default cannot operate at $t=1$. At $t=2$ firms that default are added to the number of those that do not operate. At $t=13$ the cohort of firms that defaulted at $t=1$ can again operate, which

\footnotetext{
${ }^{31}$ See http://www.nbcnews. com/business/if-obama-re-elected-youll-be-fired-ceo-tells-workers-1C6385413? streamSlug=businessmain
} 
generates the peak of both curves at $t=12$. Thus, up to $t=12$ the graph shows the fraction of firms that do not survive, 44\%, when the borrowing constraint is locally slack, and 38\% when it is tight. At $t=24$, about $37 \%$ of entrepreneurs are not operating a firm when the borrowing constraint is locally slack, and $33 \%$ with the tight constraint - the fractions in the long-run steady state are the same. In summary, in a world with slack credit constraints fewer potential entrepreneurs will operate firms, but those that do will operate at a larger scale.

According to BLS data, ${ }^{32}$ the yearly survival rates of firms is remarkably stable over time. In their initial year, about $80 \%$ of firms survive. After being established for 5 years, the probability of surviving another year increases to about $91 \%$, and to $95 \%$ after about 15 years. Thus, if one considers startups, about $30 \%$ of firms will be operating after 12 years. Since the SSBF data focuses on established firms rather than startups, we should expect the calibrated model's prediction to better fit firms that have already survived a few years. The triangles in figure 13 show the cumulative exit rates of firms that opened in 1994, conditional on surviving the first 5 years (e.g., the first data point is the fraction of such firms that exited between 2000 and 1999). The exit rates in the data are somewhat higher than those generated by the model. One reason for this difference may be that in practice some entrepreneurs quit for personal reasons rather than because their business fails, which is not captured by the model.

\section{Concluding Remarks}

Willingness to bear risk is often thought to be at the core of entrepreneurship. The goal of this paper is to understand how owner risk aversion affects small firms and how forward looking entrepreneurs use firm scale, capital structure, default and consumption to manage the significant business risks they face. We find that small differences in risk preference are sufficient to match SSBF data. The empirical distributions we match (net worth, firm size, capital structure) show substantial heterogeneity, yet the underlying heterogeneity in risk implied by the model is modest. More risk averse entrepreneurs run smaller, more highly leveraged firms with more negative equity than their less risk averse counterparts. Entrepreneurs at the lower end of our risk aversion range are willing to forgo consumption to grow their firms in the hope of future rewards that may never materialize.

In a static model firms default if and only if they have negative equity in the terminal period, and more leveraged entrepreneurs would therefore default at a higher rate. In a dynamic model a firm has a continuation value, which in turn depends on the project's scale, the firm's financial

\footnotetext{
${ }^{32} \mathrm{http}$ ://www.bls.gov/bdm/us_age_naics_00_table7.txt
} 
structure and the owner's net-worth. To better understand default in a dynamic setting, we decompose the decision into its constituent parts: the level of indebtedness, the entrepreneur's ability to inject personal funds into the firm, and the entrepreneur's consumption loss from not being able to operate a firm, which influences the entrepreneurs willingness to avoid default. We analyze how the components vary with risk aversion.

We use a composite lender to aggregate the many sources from which firms obtain loans banks, trade credit associations, leasing companies, and credit cards. In future work it would be useful to model the problems of these different lenders. For example, it would be instructive to consider the problem of a bank that must attract deposits and make loans, subject to default risk and regulation. Similarly, Eisfeldt and Rampini (2008) show that trade credit and leasing are important when lenders face information and enforcement problems, as is the case for small firms. ${ }^{33}$ Also, general equilibrium effects are important in credit markets. Increased loan demand will raise the cost of external finance, which will offset some of the gains. We focus on idiosyncratic firm risk, which is particularly interesting in this setting, because firms are not tradable, and hence the owner cannot diversify this risk. Nonetheless, aggregate risk and correlated shocks would be interesting extensions to further explore the macroeconomic implications of the model.

\footnotetext{
${ }^{33}$ Our lender can infer agents' risk aversion (e.g., from their loan request), thus adverse selection and moral hazard do not occur. Paulson and Townsend (2006) distinguish limited liability from moral hazard in a model of entrepreneurship, which would be another interesting extension in our model.
} 


\section{Appendix}

\subsection{Proof}

Proof of Theorem 1. First, substitute $V_{S}(w)=w^{1-\rho} v_{S}$ and $V_{B}(w)=w^{1-\rho} v_{B}$ into the right-hand side of the objective of problem 1 and in constraint 2 . We get

$$
\begin{aligned}
V_{S}(w)=\max _{c, A, \epsilon, \bar{v}} u(c) & +\beta\left[\int_{\mathfrak{B}}((1+r)(w-\epsilon A-c))^{1-\rho} v_{B} d F(x)\right. \\
& \left.+\int_{\mathfrak{B}^{c}}(A(x-\bar{v})+(1+r)(w-\epsilon A-c))^{1-\rho} v_{S} d F(x)\right] ;
\end{aligned}
$$

Subject to:

$$
\begin{gathered}
\int_{\mathfrak{B}}(1-\delta) x d F(x)+\int_{\mathfrak{B}^{c}} \bar{v} d F(x) \geq(1-\epsilon)\left(1+r_{f}\right) \\
x \in \mathfrak{B} \Longleftrightarrow v_{B}((1+r)(w-\epsilon A-c))^{1-\rho}>v_{S}(A(x-\bar{v})+(1+r)(w-\epsilon A-c))^{1-\rho} \\
(1-\epsilon) A \leq b w \\
c, A \geq 0,0 \leq \epsilon \leq 1 .
\end{gathered}
$$

Let $\lambda>0$ and let current wealth be $w$. We must prove that $V_{S}(\lambda w)=\lambda^{1-\rho} V_{S}(w)$.

Suppose that the entrepreneur's wealth is $\lambda w$ and consumption is changed to $\lambda c$, the firm's assets to $\lambda A$, while $\epsilon$ remains unchanged. Then

$$
\begin{aligned}
& \lambda^{1-\rho} v_{B}((1+r)(w-\epsilon A-c))^{1-\rho}=v_{B}((1+r)(\lambda w-\epsilon \lambda A-\lambda c))^{1-\rho}, \text { and } \\
& \lambda^{1-\rho} v_{S}(A(x-\bar{v})+(1+r)(w-\epsilon A-c))^{1-\rho}=v_{S}(\lambda A(x-\bar{v})+(1+r)(\lambda w-\epsilon \lambda A-\lambda c))^{1-\rho} .
\end{aligned}
$$

This and (24) imply that bankruptcy set $\mathfrak{B}$ remains unchanged. Thus, (23), (25) and (26) are satisfied. Next, note that the right-hand side of the objective changes by the factor $\lambda^{1-\rho}$. Because $V_{S}(\lambda w)$ is the maximum utility of the entrepreneur given wealth $\lambda w$, it follows that

$$
V_{S}(\lambda w) \geq \lambda^{1-\rho} V_{S}(w),
$$

for all $\lambda>0$. Thus,

$$
V_{S}(w)=V_{S}\left(\frac{1}{\lambda} \lambda w\right) \geq \frac{1}{\lambda^{1-\rho}} V_{S}(\lambda w),
$$


which implies that (27) holds with equality. Substituting $w=1$ and $\lambda=w$ in (27) immediately implies that $V_{S}(w)=w^{1-\rho} v_{S}$. The proof that $V_{B}(w)=w^{1-\rho} v_{B}$ is similar.

Finally, it is straightforward to show that

$$
\begin{aligned}
& V_{S}(w)=\frac{\ln (w)}{1-\beta}+V_{S} \\
& V_{B}(w)=\frac{\ln (w)}{1-\beta}+V_{B}
\end{aligned}
$$

Lemma 1 Constraint 1 of Problem 1 binds.

Proof of Lemma 1. Immediate: Suppose by way of contradiction that constraint (1) is slack. Then $\bar{v}$ can be lowered thereby increasing the payoff in non-bankruptcy states, $V_{S}(A(x-\bar{v})+(1+$ $r)(w-\epsilon A-c))$. Thus, the objective of problem 1 increases, a contradiction. ${ }^{34}$

Lemma 2 Suppose that $\mathfrak{B}$ is non-empty. Let

$$
x^{*}=\bar{v}-\left[1-\left(\frac{v_{B}}{v_{S}}\right)^{\frac{1}{1-\rho}}\right] \frac{(1+r)(1-\epsilon A-c)}{A}
$$

Then $\mathfrak{B}=\left\{x \mid \underline{x} \leq x<x^{*}\right\}$. Conversely, if $x^{*}>\underline{x}$, then bankruptcy set $\mathfrak{B}$ is non-empty. ${ }^{35}$

Proof of Lemma 2. If the entrepreneur chooses to default, the entrepreneur's utility is

$$
u^{B}(x)=[(1+r)(1-\epsilon A-c)]^{1-\rho} v_{B} .
$$

Otherwise, if the entrepreneur does not default, then the utility is

$$
u^{S}(x)=[A(x-\bar{v})+(1+r)(1-\epsilon A-c)]^{1-\rho} v_{S} .
$$

Note that $x \in \mathfrak{B}$ if $u^{B}(x)>u^{S}(x)$ and $x \notin \mathfrak{B}$ if $u^{S}(x) \geq u^{B}(x)$.

Suppose that $u^{S}(x) \geq u^{B}(x)$. We show that $u^{S}\left(x^{\prime}\right)>u^{B}\left(x^{\prime}\right)$ for all $x^{\prime}>x$. Note that

$$
\frac{d\left(u^{S}(x)-u^{B}(x)\right)}{d x}=\frac{(1-\rho) A v_{S}}{[(1+r)(1-\epsilon A-c)]^{\rho} v_{B}}>0
$$

\footnotetext{
${ }^{34}$ The direct effect is to increase the entrepreneur's payoff by decreasing required payments to the lender and the indirect effect is to lower the bankruptcy probability.

${ }^{35}$ At realization $x^{*}$, the entrepreneur is indifferent between default and continuing to operate the firm. Thus, (2) must hold with equality. Solving (2) for $x^{*}$ implies (28).
} 
Thus, $u^{S}(x)-u^{B}(x) \geq 0$ implies that $u^{S}\left(x^{\prime}\right)>u^{B}\left(x^{\prime}\right)$ for all $x^{\prime}>x$. Similarly, $u^{B}(x)>u^{S}(x)$ implies $u^{B}\left(x^{\prime}\right)>u^{S}\left(x^{\prime}\right)$ for all $x^{\prime}<x$. Let $x^{*}$ solve $u^{B}\left(x^{*}\right)=u^{S}\left(x^{*}\right)$. Then the bankruptcy set is given by $\mathfrak{B}=\left\{x \mid \underline{x} \leq x<x^{*}\right\}$. (29) and (30) imply

$$
[(1+r)(1-\epsilon A-c)]\left(\frac{v_{B}}{1-\rho}\right)^{1-\rho}=\left[A\left(x^{*}-\bar{v}\right)+(1+r)(1-\epsilon A-c)\right]\left(\frac{v_{S}}{1-\rho}\right)^{1-\rho},
$$

which implies (28).

Now suppose that $x^{*}$ is given by (28) and $x^{*}>\underline{x}$. Then by construction, $u^{S}\left(x^{*}\right)=u^{B}\left(x^{*}\right)$. Further, the monotonicity result established above implies $u^{B}(x)>u^{S}(x)$ for all $x<x^{*}$ and $u^{S}(x) \leq$ $u^{B}(x)$ for all $x \geq x^{*}$. Thus, the bankruptcy set is given by $\mathfrak{B}=\left\{x \mid \underline{x} \leq x<x^{*}\right\}$.

Proof of Theorem 2. Let $\Lambda\left(v_{S}\right)$ be the maximum entrepreneur utility in Problem 3. We must prove there exists $v_{S}^{*}$ such that $\Lambda\left(v_{S}^{*}\right)=v_{S}^{*}$. First let $\rho>1$. Suppose that $v_{S}=0$. Then $v_{B}<0$. As a consequence, $\Lambda(0)<0$. Now let $\hat{v}_{S}$ be the entrepreneur's expected utility from autarky.

$$
\hat{v}_{S}=\max _{c_{0}, c_{1}, \ldots} \sum_{t=0}^{\infty} \beta^{t} u\left(c_{t}\right)
$$

Subject to:

$$
\sum_{t=0}^{\infty} \frac{c_{t}}{(1+r)^{t}} \leq w \text { and } c_{0}, c_{1}, \ldots \geq 0
$$

Note that if $v_{S}=\hat{v}_{S}$ and we choose $A=0$ in problem 3 , then we get the autarky utility $\hat{v}_{S}$. Thus, optimization implies that $\Lambda\left(\hat{v}_{S}\right) \geq \hat{v}_{S}$. Since $\Lambda$ is continuous, the intermediate value theorem implies that there exists a fixed point $v_{S}^{*}$.

For $\rho \leq 1$ we re-normalize $u_{\rho}(x)=\left(x^{1-\rho}-1\right) /(1-\rho)$. Then $\lim _{\rho \rightarrow 1} u_{\rho}(x)=\ln (x)$. Suppose that $v_{S}=0$ and that $u(x)=\ln (x)$. We show that $\Lambda\left(v_{S}\right)<0$.

Let $w_{0}=1-\epsilon A$ be the amount of net-worth not invested in the firm. Because the continuation payoff from non-default is zero we get

$$
\Lambda(0)=\max _{c_{0}, c_{1}, \ldots, c_{T}} \sum_{t=0}^{T} \beta^{t} \ln \left(c_{t}\right)
$$

Subject to:

$$
\sum_{t=0}^{\infty} \frac{c_{t}}{(1+r)^{t}} \leq w_{0}
$$


Furthermore, it is sufficient to prove that the objective of (31) is negative for $w_{0}=1$, because the objective is increasing in $w_{0}$.

The first order conditions immediately reveal that

$$
c_{t}=(1+r)^{t} \beta^{t} c_{0}, \quad c_{0}=\frac{1-\beta}{1-\beta^{T+1}} .
$$

Substituting (32) into the objective of (31) yields

$$
\sum_{t=0}^{T} \beta^{t} \ln \left((1+r)^{t} \beta^{t}\right)+\sum_{t=0}^{T} \beta^{t} \ln \left(c_{0}\right)
$$

If $\beta(1+r) \leq 1$ then (33) is strictly less than 0 . Thus, there exists $\bar{r}(\beta)$ with $(1+\bar{r}(\beta)) \beta>1$ such that $\Lambda(0)<0$ for all $r \leq \bar{r}(\beta)$. By continuity there exists $\underline{\rho}<1$ such that $\Lambda(0)<0$ for $\rho \geq \underline{\rho}$. Finally, $\Lambda\left(\hat{v}_{S}\right) \geq \hat{v}_{S}$ for the autarky level of utility $\hat{v}_{S}$. Thus, continuity of $\Lambda$ implies the existence of a fixed point $v_{S}^{*}$.

Proof of Theorem 3. Let $C_{t, \rho}, t \in \mathbb{N}$ be the stochastic process that describes optimal consumption when risk aversion is $\rho$, starting with one unit of endowment at $t=0$. Let $u_{\rho}$ be the CRRA utility function with relative risk aversion $\rho$.

Let $c_{\rho}$ be given by

$$
\sum_{t=0}^{\infty} \beta^{t} u_{\rho}\left(c_{\rho}\right)=\frac{u_{\rho}\left(c_{\rho}\right)}{1-\beta}=\sum_{t=0}^{\infty} \beta^{t} E_{t}\left[u_{\rho}\left(C_{t, \rho}\right)\right]
$$

Let $\rho<\sigma$. Then there exists a strictly increasing and strictly concave function $h$ such that $h\left(u_{\rho}\right)=$ $u_{\sigma}$. Thus, (34) implies

$$
\begin{aligned}
u_{\sigma}\left(c_{\sigma}\right) & =(1-\beta) \sum_{t=0}^{\infty} \beta^{t} E_{t}\left[u_{\sigma}\left(C_{t, \sigma}\right)\right]=(1-\beta) \sum_{t=0}^{\infty} \beta^{t} E_{t}\left[h\left(u_{\rho}\left(C_{t, \sigma}\right)\right)\right] \\
& <(1-\beta) \sum_{t=0}^{\infty} \beta^{t} h\left(E_{t}\left[u_{\rho}\left(C_{t, \sigma}\right)\right]\right)<h\left((1-\beta) \sum_{t=0}^{\infty} \beta^{t} E_{t}\left[u_{\rho}\left(C_{t, \sigma}\right)\right]\right) \\
& \leq h\left((1-\beta) \sum_{t=0}^{\infty} \beta^{t} E_{t}\left[u_{\rho}\left(C_{t, \rho}\right)\right]\right)=h\left(u_{\rho}\left(c_{\rho}\right)\right)=u_{\sigma}\left(c_{\rho}\right) .
\end{aligned}
$$

Thus, if we index $v_{S}$ by $\rho$ to show dependence of $v_{S}$ on risk-aversion, (35) implies

$$
c_{\rho}=\left(v_{S, \rho}(1-\beta)(1-\rho)\right)^{\frac{1}{1-\rho}}
$$

where $c_{\rho}$ is strictly decreasing in $\rho$. 
Next, consider the bankruptcy problem, which for $T=\infty$ reduces to

$$
v_{B, \rho}=\max _{c_{t}} \sum_{t=0}^{\infty} \beta^{t} u_{\rho}\left(c_{t}\right), \text { s.t. } \sum_{t=0}^{\infty} \frac{c_{t}}{(1+r)^{t}}=1
$$

The first order conditions of (37) immediately imply $\beta^{t}(1+r)^{t} u_{\sigma}^{\prime}\left(c_{t}\right)=\beta^{t+1}(1+r)^{t+1} u_{\sigma}^{\prime}\left(c_{t+1}\right)$. Thus, $\beta(1+r)=1$ implies that $c_{t}=c_{t+1}$, i.e., consumption is constant and independent of risk aversion $\sigma$, which we denote by $c_{B}$. Thus, (37) implies

$$
c_{B}=\left(v_{B, \rho}(1-\beta)(1-\rho)\right)^{\frac{1}{1-\rho}} .
$$

Thus, the consumption loss

$$
1-\left(\frac{v_{B, \rho}}{v_{S, \rho}}\right)^{\frac{1}{1-\rho}}=1-\frac{c_{B}}{c_{S, \rho}}
$$

is decreasing in $\rho$.

Note that the second statement of the theorem follows from continuity.

Proof of Theorem 4. We consider the case with the locally slack borrowing constraint. Thus, (7) is the only binding constraint, and we can use the constraint to implicitly solve for $\bar{v}$ as a function of $A, \epsilon$, and $c$.

Let $u_{\rho}$ be the CRRA utility function with risk aversion $\rho$. For any risk aversion parameters $\sigma>\rho$, there exists a strictly increasing and strictly concave function $h$ such that $h\left(u_{\rho}\right)=u_{\sigma}$.

Using the definition of $c_{B}$ and $c_{S, \rho}$ from the proof of Theorem 3, define

$$
\theta(x ; \rho, A, \epsilon, c)=\max \left\{c_{B}[(1+r)(1-\epsilon A-c)], c_{S, \rho}[A(x-\bar{v}(A, \epsilon, c))+(1+r)(1-\epsilon A-c)]\right\}
$$

Then the optimal $A, \epsilon$, and $c$ must solve

$$
\max _{A, \epsilon, c} \frac{u_{\rho}(c)}{\beta}+\int u_{\rho}(\theta(x ; \rho, A, \epsilon, c)) d F(x)
$$

We start with the first-order conditions with respect to $A$. To shorten notation, we drop the arguments $\epsilon$ and $c$ from $\theta$. Thus, we get

$$
\int u_{\rho}^{\prime}\left(\theta\left(x ; \rho, A_{\rho}\right)\right) \frac{\partial}{\partial A} \theta\left(x ; \rho, A_{\rho}\right) d F(x)=0
$$

where

$$
\left.\frac{\partial}{\partial A} \theta(x ; \rho, A)\right)=-(1+r) \epsilon c_{B} \mathbf{1}_{\left\{x<x^{*}(A)\right\}}(x)+\left[\left(x-\bar{v}-A \frac{\partial \bar{v}(A)}{\partial A}\right)-(1+r) \epsilon\right] c_{S, \rho} \mathbf{1}_{\left\{x \geq x^{*}(A)\right\}}(x) .
$$


Using the fact that $u_{\sigma}(\cdot)=h\left(u_{\rho}(\cdot)\right)$, the optimal asset level $A_{\sigma}$ satisfies

$$
\left.\int h^{\prime}\left(u_{\rho}\left(\theta\left(x ; \sigma, A_{\sigma}\right)\right)\right) u_{\rho}^{\prime}\left(\theta\left(x ; \sigma, A_{\sigma}\right)\right) \frac{\partial}{\partial A} \theta\left(x ; \rho, A_{\sigma}\right)\right) d F(x)=0 .
$$

Note that there exists $\hat{x}_{\sigma}$ such that $\frac{\partial}{\partial A} \theta\left(x ; \rho, A_{\sigma}\right) \leq 0$ for all $x \leq \hat{x}_{\sigma}$ and $\frac{\partial}{\partial A} \theta\left(x ; \rho, A_{\sigma}\right)>0$ for all $x>\hat{x}_{\sigma}$. Let $\bar{h}=h^{\prime}\left(u_{\rho}\left(\theta\left(\hat{x}_{\sigma} ; \sigma, A_{\sigma}\right)\right)\right)$. Since $h^{\prime}$ is strictly decreasing, it follows that

$$
\begin{aligned}
0= & \int h^{\prime}\left(u_{\rho}\left(\theta\left(x ; \sigma, A_{\sigma}\right)\right)\right) u_{\rho}^{\prime}\left(\theta\left(x ; \sigma, A_{\sigma}\right)\right) \frac{\partial}{\partial A} \theta\left(x ; \sigma, A_{\sigma}\right) d F(x) \\
& <\bar{h} \int u_{\rho}^{\prime}\left(\theta\left(x ; \sigma, A_{\sigma}\right)\right) \frac{\partial}{\partial A} \theta\left(x ; \sigma, A_{\sigma}\right) d F(x)
\end{aligned}
$$

We next show that decreasing $\sigma$ to $\rho$ raises the right-hand side of (45).

$$
\begin{aligned}
& \frac{\partial}{\partial \sigma} \int u_{\rho}^{\prime}\left(\theta\left(x ; \sigma, A_{\sigma}\right)\right) \frac{\partial}{\partial A} \theta\left(x ; \sigma, A_{\sigma}\right) d F(x)=\frac{\partial}{\partial \sigma} \int_{x^{*}}^{\bar{x}} u_{\rho}^{\prime}\left(\theta\left(x ; \sigma, A_{\sigma}\right)\right) \frac{\partial}{\partial A} \theta\left(x ; \sigma, A_{\sigma}\right) d F(x) \\
& =\int_{x^{*}}^{\bar{x}} u_{\rho}^{\prime \prime}\left(\theta\left(x ; \sigma, A_{\sigma}\right)\right) \frac{\left.\theta\left(x ; \sigma, A_{\sigma}\right)\right)}{c_{S, \sigma}} \frac{\partial c_{S, \sigma}}{\partial \sigma}+u_{\rho}^{\prime}\left(\theta\left(x ; \sigma, A_{\sigma}\right)\right) \frac{\left.\theta\left(x ; \sigma, A_{\sigma}\right)\right)}{\partial A} \frac{1}{c_{S, \sigma}} \frac{\partial c_{S, \sigma}}{\partial \sigma} d F(x) \\
& -\frac{\partial x^{*}}{\partial \sigma} u_{\rho}^{\prime}\left(\theta\left(x^{*} ; \sigma, A_{\sigma}\right)\right)\left[\left(x^{*}-\bar{v}-A \frac{\partial \bar{v}(A)}{\partial A}\right) c_{S, \rho}-(1+r) \epsilon\left(c_{S, \rho}-c_{B}\right)\right] f\left(x^{*}\right) \\
& =\frac{\partial c_{S, \sigma}}{\partial \sigma} \int_{x^{*}}^{\bar{x}} u_{\rho}^{\prime}\left(\theta\left(x ; \sigma, A_{\sigma}\right)\right)\left(\frac{u_{\rho}^{\prime \prime}\left(\theta\left(x ; \sigma, A_{\sigma}\right)\right) \theta\left(x ; \sigma, A_{\sigma}\right)}{u_{\rho}^{\prime}\left(\theta\left(x ; \sigma, A_{\sigma}\right)\right) c_{S, \sigma}}+\frac{\left.\theta\left(x ; \sigma, A_{\sigma}\right)\right)}{\partial A} \frac{1}{c_{S, \sigma}}\right) d F(x) \\
& -\frac{\partial x^{*}}{\partial \sigma} u_{\rho}^{\prime}\left(\theta\left(x^{*} ; \sigma, A_{\sigma}\right)\right)\left[\left(x^{*}-\bar{v}-A \frac{\partial \bar{v}(A)}{\partial A}\right) c_{S, \rho}-(1+r) \epsilon\left(c_{S, \rho}-c_{B}\right)\right] f\left(x^{*}\right) \\
& =\frac{1}{c_{S, \sigma}} \frac{\partial c_{S, \sigma}}{\partial \sigma} \int_{x^{*}}^{\bar{x}} u_{\rho}^{\prime}\left(\theta\left(x ; \sigma, A_{\sigma}\right)\right)\left(-\rho+\frac{\partial}{\partial A} \theta\left(x ; \sigma, A_{\sigma}\right)\right) d F(x) \\
& -\frac{\partial x^{*}}{\partial \sigma} u_{\rho}^{\prime}\left(\theta\left(x^{*} ; \sigma, A_{\sigma}\right)\right)\left[\left(x^{*}-\bar{v}-A \frac{\partial \bar{v}(A)}{\partial A}\right) c_{S, \rho}-(1+r) \epsilon\left(c_{S, \rho}-c_{B}\right)\right] f\left(x^{*}\right)
\end{aligned}
$$

Theorem 3 proves that increasing $\sigma$ lowers $c_{S, \sigma}$. Hence $\frac{\partial c_{S, \sigma}}{\partial \sigma}<0$. Further, (45) and $\frac{\partial}{\partial A} \theta\left(x ; \sigma, A_{\sigma}\right)<$ 0 for $x<x^{*}$ implies

$$
0<\int_{0}^{\bar{x}} u_{\rho}^{\prime}\left(\theta\left(x ; \sigma, A_{\sigma}\right)\right) \frac{\partial}{\partial A} \theta\left(x ; \sigma, A_{\sigma}\right) d F(x)<\int_{x^{*}}^{\bar{x}} u_{\rho}^{\prime}\left(\theta\left(x ; \sigma, A_{\sigma}\right)\right) \frac{\partial}{\partial A} \theta\left(x ; \sigma, A_{\sigma}\right) d F(x) .
$$

Thus,

$$
\frac{1}{c_{S, \sigma}} \frac{\partial c_{S, \sigma}}{\partial \sigma} \int_{x^{*}}^{\bar{x}} u_{\rho}^{\prime}\left(\theta\left(x ; \sigma, A_{\sigma}\right)\right)\left(-\rho+\frac{\partial}{\partial A} \theta\left(x ; \sigma, A_{\sigma}\right)\right) d F(x)<0,
$$

for all sufficiently small $\rho$. Further, if the default probability is sufficiently small, then the singlepeakedness of the return distribution ensures that $f\left(x^{*}\right)$ is small. Thus, the derivative in (46) is negative. This, and (45) imply

$$
\left.\int_{x^{*}}^{\bar{x}} u_{\rho}^{\prime}\left(\theta\left(x ; \rho, A_{\sigma}\right)\right) \frac{\partial}{\partial A} \theta\left(x ; \rho, A_{\sigma}\right)\right) d F(x)>0 .
$$


At the solution of the optimization problem, the objective must be locally concave. At $A_{\sigma}$ the partial derivative is positive, i.e., in order to obtain the optimum we must increase $A$ from $A_{\sigma}$, hence $A_{\rho}>A_{\sigma}$, i.e., asset are decreasing in risk aversion.

The proof that $\epsilon$ decreases with risk aversion is similar. To simplify notation we drop $c$ and $A$ in function $\theta$ to get,

$$
\frac{\partial}{\partial \epsilon} \theta(x ; \rho, \epsilon)=-(1+r) A c_{B} \mathbf{1}_{\left\{x<x^{*}(\epsilon)\right\}}(x)+\left[A \frac{\partial \bar{v}(A)}{\partial \epsilon}-(1+r) A\right] c_{S, \rho} \mathbf{1}_{\left\{x \geq x^{*}(\epsilon)\right\}}(x) .
$$

The first order conditions for an entrepreneur with risk aversion $\rho$ is

$$
\int u_{\rho}^{\prime}\left(\theta\left(x ; \rho, \epsilon_{\rho}\right)\right) \frac{\partial}{\partial \epsilon} \theta\left(x ; \rho, \epsilon_{\rho}\right) d F(x)=0,
$$

and for risk aversion $\sigma$

$$
\left.\int h^{\prime}\left(u_{\rho}\left(\theta\left(x ; \sigma, \epsilon_{\sigma}\right)\right)\right) u_{\rho}^{\prime}\left(\theta\left(x ; \sigma, \epsilon_{\sigma}\right)\right) \frac{\partial}{\partial \epsilon} \theta\left(x ; \rho, \epsilon_{\sigma}\right)\right) d F(x)=0 .
$$

Note that (43) implies that $\frac{\partial}{\partial \epsilon} \theta(x ; \rho, \epsilon)<0$ for all default states. Thus, for (50) to be satisfied, $\frac{\partial}{\partial \epsilon} \theta(x ; \rho, \epsilon)>0$ for all non-default states.

The same argument as in (45) can therefore be applied to prove that

$$
\left.\int u_{\rho}^{\prime}\left(\theta\left(x ; \sigma, \epsilon_{\sigma}\right)\right) \frac{\partial}{\partial \epsilon} \theta\left(x ; \sigma, \epsilon_{\sigma}\right)\right) d F(x)>0
$$

Thus, we must increase $\epsilon$ from $\epsilon_{\sigma}$ to get to the optimal value $\epsilon_{\rho}$. Hence $\epsilon$ is decreasing in risk aversion.

\subsection{Construction of the Distribution of Firm Returns}

Herranz, Krasa, and Villamil (2009) use the 1993 SSBF to compute the ROA because it includes interest payments. They exclude unincorporated firms because the SSBF data do not account for the entrepreneur's wage from running the firm. They assume that all firms have access to the same constant returns to scale "blue print" technology, thus the return per unit of asset for a particular firm is a sample point from the distribution of this technology. The firm's nominal after-tax ROA is:

$$
x=\frac{\text { Profit after taxes }+ \text { Interest Paid }}{\text { Assets }}+1 .
$$

Interest paid is added to after tax profit because the ROA must include payments to debt and equity holders. ${ }^{36}$ The nominal rate is adjusted by $3 \%$ for inflation (BLS CPI 1993). ROA is computed

\footnotetext{
${ }^{36}$ We use after tax returns as this is relevant for an entrepreneur to decide how much net-equity to invest.
} 
instead of ROE because many firms had negative equity (about 16\% in the $1993 \mathrm{SSBF}$ and $21 \%$ in 1998). Many of these firms stay in business because owners use personal funds to "bail out the firm." Computing a ROA and modeling owners' allocations of equity and debt accounts for this. ${ }^{37}$

\subsection{Numerical Procedure}

Given model parameters, compute solutions to problem 3 as follows. For fixed $v_{S}$, use the first order conditions to solve for the optimum. (9) is always slack, since $c+\epsilon A=1$ would imply zero future consumption. We need only verify if (10) and (or) (11) bind by checking for positive Lagrange multipliers in the first order conditions. Inserting the solution of the first order conditions into the objective yields $\Lambda\left(v_{S}\right)$. To find a fixed point, compute slope $\Lambda^{\prime}\left(v_{S}\right)$ by the Envelope Theorem or compute the difference of $\Lambda$ between $v_{S}$ and a point $v_{S}^{\prime}$, giving solution $\epsilon, A, c, \bar{v}$. Section 4.1 explains how to go from these point estimates to cdfs. Compute $\underline{\rho}$ from the first order condition using the fact that $v_{S} \rightarrow \infty$ as $\rho \downarrow \underline{\rho} .^{38}$

Table 6: Comparative statics for $T$ : Fix $r_{f}=1.2 \%, r=4.5 \%, \beta=0.97, \delta=0.10$

\begin{tabular}{|c|c|c|c|c|c|c|c|c|c|c|c|c|}
\hline$T$ & $\mathbf{6}$ & $\mathbf{7}$ & $\mathbf{8}$ & $\mathbf{9}$ & $\mathbf{1 0}$ & $\mathbf{1 1}$ & $\mathbf{1 2}$ & $\mathbf{1 3}$ & $\mathbf{1 4}$ & $\mathbf{1 5}$ & $\mathbf{1 6}$ & $\mathbf{2 0}$ \\
\hline med $A \%$ & 56.2 & 54.4 & 52.7 & 51.1 & 49.6 & 48.1 & 46.7 & 45.4 & 44.3 & 43.3 & 42.4 & 38.9 \\
default\% & 6.1 & 5.6 & 5.3 & 5.0 & 4.7 & 4.4 & 4.2 & 4.0 & 3.8 & 3.6 & 3.5 & 2.9 \\
cons.\% & 3.7 & 3.7 & 3.7 & 3.7 & 3.7 & 3.6 & 3.6 & 3.6 & 3.6 & 3.6 & 3.6 & 3.6 \\
neg eq\% & 8.4 & 8.8 & 9.3 & 9.7 & 10.0 & 10.6 & 11.1 & 11.9 & 13.4 & 15.1 & 17.0 & 21.0 \\
\hline
\end{tabular}

\subsection{The Impact of Bankruptcy Policy: $T, \delta$}

Bankruptcy Exclusion Period T: Consider the effect of changes in $T$ on the owner's payoff, where longer exclusion raises the penalty of bankruptcy. Table 6 fixes $\mu, \sigma, b$, and evaluates the effect of altering the exclusion period from the benchmark $T=11$ for the model with the tight constraint. As $T$ decreases default increases rapidly. Firm size increases, measured by median asset level $A$. Because $b$ is fixed, the decrease in total investment results in a decrease in equity and an increase in debt, which raises negative equity. One of the main economic arguments in support of recent U.S. bankruptcy reform was that more stringent bankruptcy rules lower interest rates,

\footnotetext{
${ }^{37}$ Computing ROE is misleading for firms near distress. For firms with low but positive equity, small profit gives a high percentage return. Also, many loans are collateralized; book value of equity understates owner contribution (the "correct" value of equity).

${ }^{38}$ Choose a large value for $v_{S}$, solve for the remaining parameters including $\rho$, which approximates $\underline{\rho}$. In other words, rather than solving the fixed point problem for $v_{S}$, solve it for $\rho$.
} 
Table 7: Effects as $T$ Varies: \% change in net-worth compared to benchmark

\begin{tabular}{|c|c|c|c|c|c|c|c|c|c|}
\hline risk aversion $\rho$ & $\mathbf{0 . 9}$ & $\mathbf{1 . 2}$ & $\mathbf{1 . 5}$ & $\mathbf{1 . 8}$ & $\mathbf{2 . 1}$ & $\mathbf{2 . 5}$ & $\mathbf{3 . 0}$ & $\mathbf{3 . 5}$ & $\mathbf{4 . 0}$ \\
\hline$T=6$ & 36.9 & 11.2 & 7.7 & 6.1 & 5.0 & 3.9 & 3.1 & 2.6 & 2.2 \\
$T=8$ & 19.8 & 5.5 & 3.9 & 3.0 & 2.4 & 1.9 & 1.5 & 1.3 & 1.1 \\
$T=10$ & 6.3 & 1.3 & 1.1 & 0.8 & 0.7 & 0.5 & 0.4 & 0.3 & 0.3 \\
$T=11$ & - & - & - & - & - & - & - & - & - \\
$T=12$ & -3.6 & -0.7 & -0.9 & -0.7 & -0.5 & -0.4 & -0.3 & -0.3 & -0.2 \\
$T=14$ & -7.6 & -4.4 & -2.1 & -1.8 & -1.4 & -1.0 & -0.8 & -0.6 & -0.5 \\
$T=16$ & -12.7 & -6.5 & -3.8 & -2.4 & -2.0 & -1.5 & -1.1 & -0.9 & -0.7 \\
\hline
\end{tabular}

and therefore help borrowers. The loan rate indeed decreases as $T$ increases. However, stricter bankruptcy provides less insurance against bad realizations, and this effect dominates. Table 7 shows that lowering the exclusion period increases the owner's payoff, and the model implies that it is optimal to set $T$ as low as possible. Decreasing $T$ is beneficial because it allows a firm to restart and be productive, in accordance with the historical rationale for bankruptcy, though $T=0$ may not be possible or desirable. ${ }^{39}$ The downside of lower a $T$ is increased risk absorbed by lenders such as banks, whose own risk of default increases, a cost not accounted for in our model.

The tradeoff between insurance provided by firm bankruptcy and higher interest rates induced by increased default has been analyzed for consumer bankruptcy by Chatterjee, Corbae, Nakajima, and Rios-Rull (2007) and Livshits, MacGee, and Tertilt (2007). In both models consumers trade off insurance against health, divorce or family shocks versus consumption smoothing; the signs of the tradeoffs differ but the welfare effects are modest. ${ }^{40}$ Meh and Terajima (2008) add unincorporated entrepreneurs to the model, and find a larger welfare effect of $1.78 \%$. In contrast, table 7 reports strong effects from reducing the exclusion penalty in our model, particularly for agents with low levels of risk aversion. The main reason for the difference between our model of firm bankruptcy and the consumer bankruptcy models is that reducing the punishment period encourages entrepreneurs to invest more in their firms and operate at a larger scale, which increases

\footnotetext{
${ }^{39}$ We have complete information, but information frictions would make a very low $T$ undesirable. Suppose entrepreneurs could choose between the blueprint return distribution and an alternative with more risk than is socially desirable. In an institutional environment in which strong ex ante and interim screening mechanisms exist and penalties are credible, a small $T$ can be sufficient to avoid moral hazard or adverse selection. In contrast, a country with poor institutions would require a larger $T$ to deter entrepreneurs from choosing the alternative distribution, thus generating additional inefficiencies.

${ }^{40}$ In our model credit is secured, for example by a house, and "bad luck" is a poor return $x$ rather than the health, job, divorce or family shocks in the consumer models. The first paper finds that when punishment is reduced from 10 to 5 years welfare drops by $0.05 \%$, thus the negative effect from a higher interest rate and tighter borrowing constraint slightly dominates the insurance benefit of a shorter punishment period. The second paper shows that the insurance effect is sometimes weakly dominant, but again the effect is modest.
} 
output. In this sense, even though we do not find extreme variations in $\rho$, risk interacts with the dynamic decision problem, return distribution and bankruptcy rules to have an important effect on some (heterogeneous) agents, namely those that invest most heavily in their firms.

Bankruptcy Cost $\delta$ : One can show that changing the costs of bankruptcy has only a minor effect on the model's endogenous parameters. However, if $\delta$ is very large and there are large fixed costs to creditors to recover payments in default, agents will try to avoid costly bankruptcy, through debt forgiveness or renegotiation. The static model of Krasa, Sharma, and Villamil (2008) shows that when courts are sufficiently inefficient substantial deadweight losses are possible.

\subsection{Counterfactual Exercise: Empirical vs. Normal Returns}

The features of return distribution $f(x)$ are important for understanding entrepreneur behavior. We conduct two counterfactual experiments to show that the return distribution is important. The experiments replace the empirical ROA distribution computed from SSBF data, keeping all other benchmark settings the same, with two different normal distributions.

Best Fit Normal Distribution. Let $\phi_{\mu, \sigma}$ be the density of a normal distribution with mean $\mu$ and standard deviation $\sigma$ and $f$ be the density of the SSBF distribution. Solve $\min _{\mu, \sigma} \sup _{x}\left|\phi_{\mu, \sigma}(x)-f(x)\right|$ to find a normal distribution that best approximates the empirical density function. The resulting values are $\mu=1.193$ and $\sigma=0.394$. In order to fit the "middle" this normal distribution has less mass in the tails and, as a consequence, is less risky. Thus, when re-calibrating the model, median risk aversion increases from 1.55 to 2.33 but at the same time, for given $\rho$, the lower project risk in this normal distribution encourages entrepreneurs to run larger firms. Default is lower, again because this normal distribution has a thinner lower tail. Finally, the thinner upper tail implies that less firms will be "lucky" and have a very good realization. In order to match the distribution of net-worth invested, firms must be more leveraged: Given two solvent firms with the same realization, a more leveraged firm earns a higher return because the owner receives a higher residual after making the fixed debt payment. ${ }^{41}$ The somewhat higher level of debt also implies that more low realizations will result in negative equity, and the predicted percentage of firms with negative equity increases from $10.6 \%$ to $13.7 \%$.

Normal Distribution with SSBF $\mu, \sigma$. Figure 1 compares the SSBF pdf with a normal distribution with the same mean and standard deviation. Table 8 shows the results for this distribution are significantly at odds with the data, highlighting the importance of the return distribution. First,

\footnotetext{
${ }^{41}$ This also explains the higher value of $b$.
} 
Table 8: Counterfactual Experiment: Normal Distributions

\begin{tabular}{|c|c|c|c|c|}
\hline Parameter & Data & $\begin{array}{c}\text { Empirical } f(x) \\
\text { SSBF } 1993\end{array}$ & $\begin{array}{c}\text { Best Fit Normal } \\
\mu=1.193, \sigma=0.3938\end{array}$ & $\begin{array}{c}\text { Normal } \\
\mu=1.300, \sigma=1.193\end{array}$ \\
\hline$\mu$ & $1-3$ & 1.55 & 2.33 & $4.4 * 10^{8}$ \\
$\sigma$ & NA & .83 & 1.11 & $7.9 * 10^{8}$ \\
b\% & NA & 21.5 & 30.0 & 23.4 \\
fit & NA & 0.042 & 0.040 & .045 \\
median A\% & {$[43.1,51.9]$} & 48.1 & 54.7 & 38.6 \\
default \% & 3.5 & 4.4 & 1.5 & 61.0 \\
cons. \% & $3-5$ & 3.6 & 4.9 & 3.1 \\
neg. Eq \% & 15.7 & 10.6 & 13.7 & 64.4 \\
\hline
\end{tabular}

the fat tails lead to $\mu$ and $\sigma$ with all point mass at $\underline{\rho}$ and $\bar{\rho}$, where $\bar{\rho}$ is the highest risk aversion for which we compute a solution. Generally, we can choose $\bar{\rho}$ sufficiently high that the mass above $\bar{\rho}$ is negligible; this cannot be done for this normal distribution with fat tails and $\bar{\rho}$ affects the results. ${ }^{42}$ Second, the model predictions in the last column of table 8 are implausible.

\footnotetext{
${ }^{42}$ Upper bound $\bar{\rho}$ is needed for computation; it is impossible to compute solutions for a fine grid $[\underline{\rho}, \infty]$.
} 


\section{References}

Alvarez, F. and U. Jermann (2000). Efficiency, equilibrium and asset pricing with risk of default. Econometrica 68, 775-797.

Arellano, C. (2008). Default risk and income fluctuations in emerging economies. The American Economic Review 98(3), 690-712.

Athreya, K. (2004). Shame as ever it was: Stigma and personal bankruptcy. Economic Quarterly, FRB of Richmond 90, 1-19.

Boissay, F. and R. Gropp (2007). Trade credit defaults and liquidity provision by firms. Working Paper No. 753, European Central Bank.

Boyd, J. and B. Smith (1994). How good are standard debt contracts? Stochastic versus non stochastic monitoring in a costly state verification environment. Journal of Business 67, $539-561$.

Bris, A., I. Welch, and N. Zhu (2006). The cost of bankruptcy: Chapter 7 liquidation versus chapter 11 reorganization. Journal of Finance 111, 1253-1303.

Cagetti, M. and M. De Nardi (2006). Entrepreneurship, frictions, and wealth. Journal of Political Economy 114(5), 835-870.

Cantillon, R. (1755). Essai Sur La Nature Du Commerce en Général. London: Fletcher Gyles.

Chatterjee, S., D. Corbae, M. Nakajima, and V. Rios-Rull (2007). A quantitative theory of unsecured consumer credit with risk of default. Econometrica 75, 1525-1589.

Chen, H., J. Miao, and N. Wang (2010). Entrepreneurial finance and nondiversifiable risk. Review of Financial Studies 23(12), 4348-4388.

Eisfeldt, A. and A. Rampini (2008). Leasing, ability to repossess, and debt capacity. Review of Financial Studies 21, 289-309.

Gale, D. and M. Hellwig (1985). Incentive-compatible debt contracts: The one period problem. Review of Economic Studies 52, 647-663.

Glennon, D. and P. Nigro (2005). Measuring the default risk of small business loans: A survival analysis approach. Journal of Money Credit and Banking 37, 923-947.

Glover, A. and J. Short (2011). Bankruptcy, incorporation, and the nature of entrepreneurial risk. Technical report, http://EconPapers . repec . org/RePEc: red: sed011:836. 
Herranz, N., S. Krasa, and A. Villamil (2009). Small firms in the ssbf. Annals of Finance 5, 341-359.

Kihlstrom, R. and J. Laffont (1979). A general equilibrium entrepreneurial theory of firm formation based on risk aversion. Journal of Political Economy 87, 719-749.

Knight, F. H. (1921). Risk, Uncertainty and Profit. Boston, MA: Hart, Schaffner \& Marx; Houghton Mifflin.

Krasa, S., T. Sharma, and A. Villamil (2008). Bankruptcy and firm finance. Economic Theory 3, 595-609.

Livshits, I., J. MacGee, and M. Tertilt (2007). Consumer bankruptcy: A fresh start. American Economic Review 97, 402-418.

Martins-da Rocha, V. and Y. Vailakis (2011). Refining not-too-tight solvency constraints. Working Paper.

Mazzocco, M. (2006). Individual rather than household euler equations: Identification and estimation of individual preferences using household data. http://www.ccpr.ucla.edu/asp/Mrsch.asp.

Meh, C. and Y. Terajima (2008). Unsecured debt, consumer bankruptcy and entrepreneurship. working paper, Bank of Canada.

Mester, L. (1997). What's the point of credit scoring? Business Review 3, 3-16.

Michelacci, C. and V. Quadrini (2005). Borrowing from employees: Wage dynamics with financial constraints. Journal of the European Economic Association 3(2-3), 360-369.

Paulson, A. and R. Townsend (2006). Distinguishing limited liability from moral hazard in a model of entrepreneurship. Journal of Political Economy 114, 100-145.

Townsend, R. (1979). Optimal contracts and competitive markets with costly state verification. Journal of Economic Theory 2, 1-29.

Vereshchagina, G. and H. Hopenhayn (2009). Risk taking by entrepreneurs. American Economic Review 99, 1808-1830. 